\title{
Observed and simulated water and energy budget components at SCAN sites in the lower Mississippi Basin
}

\author{
Gabriëlle J. M. De Lannoy, ${ }^{1,2 *}$ Julie Ufford, ${ }^{1}$ Alok K. Sahoo, ${ }^{1,3}$ Paul Dirmeyer, ${ }^{4}$ \\ and Paul R. Houser ${ }^{1}$ \\ ${ }^{1}$ George Mason University and Center for Research on Environment and Water, 4041 Powder Mill Road, Suite 302, Calverton, MD 20705-3106, \\ USA \\ ${ }^{2}$ Laboratory of Hydrology and Water Management, Ghent University, Coupure links 653, B-9000 Ghent, Belgium \\ ${ }^{3}$ Department of Civil and Environmental Engineering, Princeton University, Princeton, NJ 08544, USA \\ ${ }^{4}$ Center for Ocean-Land-Atmosphere Studies, 4041 Powder Mill Road, Suite 302, Calverton, MD 20705-3106, USA
}

\begin{abstract}
:
Land surface models are typically constrained by one or a few observed variables, while assuming that the internal water and energy partitioning is sensitive to those observed variables and realistic enough to simulate unobserved variables. To verify these assumptions, in situ soil climate analysis network (SCAN) observations in the Lower Mississippi Basin (2002-2008) are analysed to quantify water and energy budget components and they are compared to Community Land Model (CLM3.5) simulations. The local soil texture is identified as a major indicator for water storage characteristics and the Normalized Difference Vegetation Index shows potential as a drought indicator in summer months. Both observations and simulations indicate a regime where, except in some summer months, evapotranspiration controls soil moisture. CLM simulations with different soil texture assignments show discharge sensitivity to soil moisture, but almost no impact on evapotranspiration and other energy balance components. The observed and simulated water budgets show a similar partitioning. However, the SCAN observed water balance does not close because of precipitation measurement errors, unobserved irrigation, lack of specific storage change measurements and errors in the computed actual evapotranspiration. The simulated heat flux partitioning differs from that 'observed', with a larger (resp. smaller) fraction of net radiation being used by latent (resp. sensible) heat flux, and unobserved freeze and thaw events. The comparison between observations and model simulations suggests that a consistent observation collection for multiple variables would be needed to constrain and improve the full set of land surface variable estimates. Copyright (C) 2010 John Wiley \& Sons, Ltd.
\end{abstract}

KEY WORDS water balance; energy balance; SCAN; land surface model; NDVI; MODIS; actual evapotranspiration; soil moisture

Received 7 January 2010; Accepted 22 July 2010

\section{INTRODUCTION}

The partitioning of terrestrial water and energy into different storages and fluxes has a large temporal and spatial variability. Changes in the surface water or temperature state either cause, or are caused by, water and heat fluxes. However, there are more state variables and pathways involved than are typically measured and measurements sufficient to close energy and water budgets are rare. This incompleteness means that land surface models are typically under-constrained and poorly calibrated. Nevertheless, the premise of simulation studies is the estimation of unobserved variables, based on these models. Here, we study the usefulness of a prototype observational in situ network to quantify regional water and energy budget components as well as to evaluate land surface model estimates of these components.

* Correspondence to: Gabriëlle J. M. De Lannoy, Present address: NASA/ GSFC, Code 610.1, Global Modeling and Assimilation Office, 8800 Greenbelt Rd, Greenbelt, MD 20771, USA.

E-mail: Gabrielle.DeLannoy@nasa.gov, Gabrielle.DeLannoy@UGent.be
The different individual water and energy budget components have been observed by a wide range of in situ and remotely sensed measurements or derived through numerical approaches. The land surface water storage state includes soil moisture, groundwater, snow, ice, intercepted vegetation water, stream and reservoir water. In snow-free regions, point profile soil moisture observations give an approximate water storage estimate, excluding the slowly varying groundwater. Most satellite measurements only measure the upper layer soil moisture. However, the gravity recovery and climate experiment (GRACE) satellite mission allows a more complete (but coarse scale) water storage assessment (Syed et al., 2005; Rodell et al., 2007; Zaitchik et al., 2008). Alternatively, the water storage can be estimated as the water balance equation residual (Duan and Schaake, 2003).

The primary incoming driving force of the land surface hydrologic system is precipitation. It is generally well monitored over land through rain gauges, weather radars and satellite observations (Ebert et al., 2007), or it can be estimated from meteorological model analyses. However, 
precipitation measurements are known to be inaccurate, especially for snow quantification. Standard precipitation gauges and satellite retrievals often underestimate the snowfall (Goodison, 1978; Tian et al., 2009).

Runoff, drainage or discharge provide an areaintegrated estimate of water leaving the terrestrial (sub-) system. Discharge is usually one of the better recorded water budget variables. Sheffield et al. (2009) studied the water balance closure over the Mississippi River basin purely using remote sensing sources. They found that streamflow estimated as the residual of a water balance budget calculation was erroneous due to large observed precipitation biases, but even with precipitation bias removal, the uncertainty in the different water balance components remained high.

Evapotranspiration is the dominant outgoing land flux and it links the water balance to the energy balance (Shuttleworth, 1992). Actual evapotranspiration ETa can be observed directly at the point scale from pans, lysimeters (Xu and Chen, 2005), eddy correlation or Bowen ratio meteorological stations (Barr et al., 1994; Pauwels and Samson, 2006), at the regional scale through scintillometers (de Bruin et al., 1995), or approximated from satellite data (Bastiaanssen et al., 1998; Clapp and Hornberger, 2006; Su et al., 2007) over larger domains. These 'measurements' often involve a number of assumptions in their computation. ETa is often calculated or modelled as the residual in water balance equations or from potential evapotranspiration estimates (Vörösmarty et al., 1998), e.g. as an output from land surface modelling. Unfortunately, ETa simulations, remote sensing products and field measurements sometimes show little agreement (Kite and Droogers, 2000), leaving the ETa as probably the most difficult balance component to estimate.

The net radiation $\mathrm{Rn}$ provides the energy available for sensible, latent and ground heat fluxes. Sensible heat measurements are usually obtained complimentary to latent heat flux measurements at eddy correlation or Bowen ratio meteorological stations, through scintillometry (Meijninger and de Bruin, 2000) or satellite estimates (Norman et al., 2000). Ground heat fluxes can be measured over heat flux plates, but this approach is often inaccurate because of space scale issues. Therefore, the ground heat flux is often assumed to be either a (constant) fraction of $\mathrm{Rn}$ or the residual of the energy balance.

Land surface modelling involves vertically solving the water and energy equations from the top of the canopy through the root zone and simultaneously solves for all the above water and energy budget components. Parameter optimization reduces model bias by improving only a few land system parameters, without optimizing all internal processes, i.e. the model structure remains a strong constraint. This issue has been addressed by using multiple objective functions in model calibration (Gupta et al., 1998; Bastidas et al., 1999; Pauwels and De Lannoy, 2010) to penalize the deviations from a set of observed variables, instead of constraining the model based on a single output variable only. Data assimilation for state updating uses state-related observations to optimize (and balance) the land surface model's state, with the expectation of improving the dependent fluxes. However, unless the modelled water and energy partitioning reflect the observed partitioning for a specific water storage or temperature state, there is no guarantee that the state updating sustainably improves the overall land surface simulations (De Lannoy et al., 2007). Furthermore, the actual partitioning may not be stationary in time (cf. climate change). Therefore, this study compares a number of point scale observed energy and water balance components to land surface model simulations prior to any data-model fusion.

Coarser scale studies have shown a large variability in the partitioning of water and energy over the Mississippi area (Rasmusson, 1968; Betts et al., 1999; Yarosh et al., 1999; Maurer et al., 2002; Feng and Houser, 2008). This paper complements the earlier studies by analysing point scale meteorological and soil moisture data from the U.S. Department of Agriculture (USDA) Natural Resource Conservation Service's (NRCS) Soil Climate Analysis Network (SCAN, (Schaefer et al., 2007)). Discharge data for individual subbasins with SCAN sites are obtained from the US Geological Survey (USGS). The Moderate Resolution Imaging Spectroradiometer (MODIS) Normalized Difference Vegetation Index (NDVI) is used to relate water storage and evapotranspiration to vegetation cover (Adegoke and Carleton, 2001; Gu et al., 2007; Wang et al., 2007). The seasonal in situ observed water and energy partitioning is compared to Community Land Model (CLM3.5) simulations.

After a description of the data and the land surface model (see section on Data and Model Description), the water and energy budget components are briefly discussed (see section on Water and Energy Balance), and special attention is given to the calculation of the evapotranspiration in the Evapotranspiration section. Observed and simulated hydrologic budget analyses are reported in the Results section, followed by the Conclusions section.

\section{DATA AND MODEL DESCRIPTION}

\section{Observations}

Hydrometeorological data from January 2002 through May 2008, as well as soil physical and vegetation information are collected at 16 SCAN sites located in the Lower Mississippi River Basin (Figure 1), with 12 sites located more specifically in the Yazoo River Basin. This relatively flat area has a silty loam texture and is mainly covered with grass and cropland. SCAN sites record hourly volumetric soil moisture at 5, 10, 20, 50 and $100 \mathrm{~cm}\left(\mathrm{SM}_{5}, \mathrm{SM}_{10}, \ldots, \mathrm{SM}_{100}\right)$, precipitation, incoming radiation, air temperature, wind speed, relative humidity, etc. Missing meteorological data are filled in using data from a neighbouring SCAN site with the highest time correlation during overlapping data time periods. For this purpose, also some closeby SCAN sites (sites 2083, 2064 and 2090, not shown) in neighbouring drainage basins are used. Missing soil moisture data are not filled in, because too little reliable data are reported. At each site the total 
amount $(\mathrm{mm})$ of available soil moisture SM in the upper $35 \mathrm{~cm}$ (approximate rooting zone water available for evapotranspiration) is calculated based on the volumetric observations (vol\%) in the upper three layers:

$$
\begin{aligned}
\mathrm{SM}= & \mathrm{SM}_{5} \times 75 \mathrm{~mm}+\mathrm{SM}_{10} \times 75 \mathrm{~mm} \\
& +\mathrm{SM}_{20} \times 200 \mathrm{~mm},
\end{aligned}
$$

which is referred to as the observed water storage $S$. The water table in the neighborhood of the SCAN sites is generally deep and not directly affecting the observed root-zone soil moisture, although the Lower Mississippi River Basin does have saturated zones for some parts of the year.

Additionally, half hourly evapotranspiration (eddy correlation), soil moisture and other meteorological data are

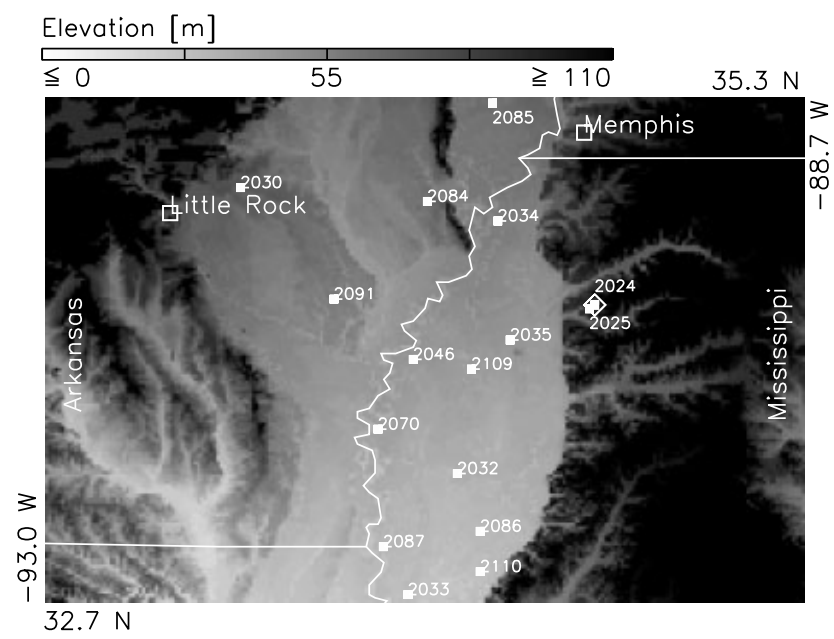

Figure 1. Digital elevation model of the studied domain. The dots mark SCAN locations situated in the Lower Mississippi drainage area. The diamond centre is at the Goodwin flux tower location obtained from a flux tower (AmeriFlux, Fluxnet, (Hargrove et al., 2003; Massman et al., 2004)) in the Goodwin Creek (GC) watershed (MS). Site specific details are listed in Table I. The discharge is estimated as an integrated value over all SCAN sites. We located each SCAN station in the smallest gauged drainage area (USGSgauged subbasins $8030204,8030207,8030209$, $8030202,8020203,8020303,8020402$ ) and calculated the unit area discharge. These unit area discharges are then averaged over all SCAN sites. Some SCAN sites are in the same observed subbasin (e.g., four sites are located in the Big Sunflower drainage unit 8030207 ) and their unit discharge is then repeatedly used in the regional average. Missing discharge data are not filled in. Time series of NDVI are extracted at each SCAN site location from global 16-day $250 \mathrm{~m}$ Terra MODIS Level 3 products (MOD13Q1, sinusoidal projection, Version V005) for the entire study period. The 16-day time series are interpolated to daily through cubic spline interpolation and monthly averages are calculated based on these daily interpolated data. For the data analysis and model evaluation, all data are converted to daily and monthly values.

\section{Land surface model}

The CLM (Oleson et al., 2007) simulates water and heat fluxes and states for individual grid cells separately. Point profiles at the SCAN locations are simulated individually, forced with locally observed meteorological SCAN forcing data, and parameterized for point local conditions of soil and vegetation. All simulations are performed with a constant hourly time step from January 2002 through May 2008 after 1 year of spinup. The vegetation parameterization at each SCAN site is taken from the standard CLM plant physiological information corresponding to the land cover reported in Table I. The

Table I. Specifications of 16 SCAN sites and the Goodwin Creek (GC) flux tower site (GWflux) situated in the Lower Mississippi

\begin{tabular}{|c|c|c|c|c|c|c|c|c|c|c|}
\hline \multirow[t]{2}{*}{ Site } & \multirow[t]{2}{*}{ No } & \multicolumn{2}{|c|}{ Location } & \multirow{2}{*}{$\begin{array}{c}\text { UMD } \\
\text { Land cover }\end{array}$} & \multicolumn{3}{|c|}{ SCAN texture } & \multicolumn{3}{|c|}{ FAO texture } \\
\hline & & Lon $(\mathrm{W})$ & Lat $(\mathrm{N})$ & & $\mathrm{C}(\%)$ & $\mathrm{Si}(\%)$ & $\mathrm{Sa}(\%)$ & $\mathrm{C}(\%)$ & $\mathrm{Si}(\%)$ & $\mathrm{Sa}(\%)$ \\
\hline Dewitt & 2091 & $91^{\circ} 21^{\prime}$ & $34^{\circ} 17^{\prime}$ & Woodland & $17 \cdot 8$ & $76 \cdot 1$ & $6 \cdot 1$ & 19 & 33 & 46 \\
\hline Lonoke farm & 2030 & $91^{\circ} 53^{\prime}$ & $34^{\circ} 51^{\prime}$ & Grassland & $14 \cdot 8$ & $76 \cdot 9$ & $8 \cdot 3$ & 19 & 33 & 46 \\
\hline Marianna & 2084 & $90^{\circ} 40^{\prime}$ & $34^{\circ} 47^{\prime}$ & Cropland & $14 \cdot 0$ & $83 \cdot 3$ & $2 \cdot 7$ & 34 & 33 & 33 \\
\hline Earle & 2085 & $90^{\circ} 27^{\prime}$ & $35^{\circ} 17^{\prime}$ & Cropland & N/A & N/A & N/A & 35 & 31 & 34 \\
\hline Mayday & 2110 & $90^{\circ} 31^{\prime}$ & $32^{\circ} 52^{\prime}$ & Wooded grassland & $63 \cdot 9$ & $29 \cdot 1$ & $1 \cdot 3$ & 21 & 34 & 45 \\
\hline Perthshire & 2046 & $90^{\circ} 54^{\prime}$ & $33^{\circ} 58^{\prime}$ & Cropland & $52 \cdot 8$ & $46 \cdot 0$ & $1 \cdot 2$ & 34 & 31 & 35 \\
\hline North Issaquena & 2087 & $91^{\circ} 04^{\prime}$ & $33^{\circ} 00^{\prime}$ & Cropland & 44.4 & $52 \cdot 0$ & 3.6 & 34 & 32 & 34 \\
\hline Beasley Lake & 2032 & $90^{\circ} 39^{\prime}$ & $33^{\circ} 23^{\prime}$ & Cropland & $43 \cdot 6$ & $51 \cdot 9$ & 4.4 & 34 & 32 & 34 \\
\hline Tunica & 2034 & $90^{\circ} 25^{\prime}$ & $34^{\circ} 41^{\prime}$ & Cropland & $33 \cdot 1$ & $45 \cdot 0$ & $21 \cdot 9$ & 34 & 32 & 34 \\
\hline Onward & 2033 & $90^{\circ} 56^{\prime}$ & $32^{\circ} 45^{\prime}$ & Deciduous broadleaf & $32 \cdot 4$ & $62 \cdot 8$ & $4 \cdot 8$ & 17 & 37 & 46 \\
\hline Scott & 2070 & $91^{\circ} 06^{\prime}$ & $33^{\circ} 37^{\prime}$ & Wooded grassland & 28.9 & $56 \cdot 7$ & $14 \cdot 4$ & 34 & 32 & 34 \\
\hline GC Timber & 2025 & $89^{\circ} 54^{\prime}$ & $34^{\circ} 14^{\prime}$ & Woodland & $22 \cdot 8$ & $76 \cdot 3$ & $0 \cdot 9$ & 24 & 26 & 50 \\
\hline GC pasture & 2024 & $89^{\circ} 52^{\prime}$ & $34^{\circ} 15^{\prime}$ & Wooded grassland & $21 \cdot 2$ & $77 \cdot 4$ & 1.4 & 24 & 26 & 50 \\
\hline Silver City & 2086 & $90^{\circ} 31^{\prime}$ & $33^{\circ} 05^{\prime}$ & Wooded grassland & $19 \cdot 6$ & $76 \cdot 9$ & $12 \cdot 1$ & 34 & 32 & 34 \\
\hline Vance & 2035 & $90^{\circ} 21^{\prime}$ & $34^{\circ} 04^{\prime}$ & Cropland & $19 \cdot 2$ & $54 \cdot 8$ & $26 \cdot 0$ & 23 & 23 & 55 \\
\hline Sandy Ridge & 2109 & $90^{\circ} 34^{\prime}$ & $33^{\circ} 40^{\prime}$ & Cropland & $11 \cdot 5$ & $26 \cdot 5$ & $62 \cdot 0$ & 23 & 23 & 54 \\
\hline GWflux & & $89^{\circ} 87^{\prime}$ & $34^{\circ} 25^{\prime}$ & Grassland & 20 & 55 & 25 & 17 & 37 & 46 \\
\hline
\end{tabular}
River Basin

The upper four SCAN sites are located in Arkansas, the other sites in Mississippi. The local SCAN texture is calculated as a weighted average over $35 \mathrm{~cm}$, while the FAO-based texture is based on a single $30 \mathrm{~cm}$ estimate. The sites are sorted based on the SCAN clay $\%$. 
seasonally evolving leaf area index (LAI) and stem area index (SAI) are both locally extracted from $1 \mathrm{~km}$ MODIS climatologies (based on years 2001-2006; (Zeng et al., 2002)). The soil profile is divided into 10 layers centered at $2.5,5,10,20,30,40,50,80,100$ and $150 \mathrm{~cm}$ depth. Because of the high soil moisture sensitivity to hydraulic parameters and hence to soil texture (Richter et al., 2004; Mostovoy and Anantharaj, 2008), one CLM simulation is performed with soil texture information extracted from the Food and Agriculture Organization (FAO) Soil Map of the World (original resolution 5 arc-min) (Reynolds et al., 1999) and a second one is performed with locally sampled SCAN point profile soil texture information. The latter scenarios mimic the effect of changing soil parameters as can be expected from a typical calibration for soil moisture (De Lannoy et al., 2006).

We do not perform any calibration, and the model is fully parameterized using observation-based information. However, most of the parameter information is only available at coarser scales and the model has inevitable shortcomings, which could (partially) be compensated for through calibration. It will be shown that changing soil parameters (cf. additional calibrating based on one observed variable, e.g. soil moisture) does not necessarily affect all the absolute model output values for this study area and it leaves the relative partitioning of the different budget components almost unchanged.

\section{WATER AND ENERGY BALANCE}

For the water balance, the incoming amount of precipitation $P$ equals the sum of the outgoing evapotranspiration ETa plus drainage and runoff $D$ and the water storage $S$ change over a period $[t: t+1]$ :

$$
P_{[t: t+1]}=\left(S_{t+1}-S_{t}\right)+\operatorname{ETa}_{[t: t+1]}+D_{[t: t+1]}(\mathrm{mm})
$$

For the observed water balance study, $P, S$ and $D$ are directly and independently measured and ETa is calculated in the Evapotranspiration section. For the observed storage $S$, only the root-zone soil moisture $\mathrm{SM}$ is included, which is the major dynamic storage component. For the simulated water balance study, CLM simulates $S$ and ETa based on physical laws with $D$ as the residual. However, CLM includes canopy water, deeper layer soil moisture, snow and ice in its storage components.

For the energy balance, the total net absorbed radiation flux $\mathrm{Rn}$ equals the sum of the ground heat flux $G$, outgoing sensible heat flux $H$ and latent heat flux $\lambda$ ETa:

$$
\mathrm{Rn}=G+H+\lambda \mathrm{ETa} \quad\left(\mathrm{W} \mathrm{m}^{-2}\right)
$$

with $\lambda$ the latent heat of evaporation for water $(\sim 2.501 \times$ $10^{6} \mathrm{~J} \mathrm{~kg}^{-1}$, temperature-dependent, (Rogers and Yau, 1989)), which converts an ETa rate $\left(\mathrm{mm} \mathrm{s}^{-1}\right)$ into a heat flux $\lambda \mathrm{ETa}\left(\mathrm{W} \mathrm{m}^{-2}\right)$. Clearly, ETa is the link between the terrestrial water and energy balance. The 'observed' Rn is calculated based on the observed solar radiation (see section on Evapotranspiration). An alternate scheme is used in CLM, which has a more complex treatment of soil and vegetation albedos. The daily $G$ is very small relative to $\mathrm{Rn}$, particularly under vegetation cover, and hence ignored in the daily observed budget. The monthly $G$ can be approximated by the difference between the following and preceeding month's air temperature (Allen et al., 1998):

$$
\begin{aligned}
& G_{\text {month }}=c_{\mathrm{S}}\left(T_{\text {month+1 }}-T_{\text {month-1 }}\right) \\
& \quad \times \text { effective depth }\left(\mathrm{MJ} \mathrm{m}^{-2} \text { month }^{-1}\right)
\end{aligned}
$$

with $c_{\mathrm{s}}$ the constant soil heat capacity (depending on the soil composition, chosen to be $2 \cdot 1 \mathrm{MJ} \mathrm{m}^{-3}{ }^{\circ} \mathrm{C}^{-1}$, (Brutsaert, 1982)). The effective depth (m) depends on the amount of days over which $G$ is calculated and is chosen to be $1 \mathrm{~m}$ in the calculation of the monthly $G$ for all sites. Even though soil properties are known to strongly affect the heat fluxes (Peters-Lidard et al., 1998), the above assumptions can be justified, given the limited magnitude of $G$ relative to the other fluxes. The monthly $H$ is then calculated as Rn- $\lambda$ ETa-G. Because $H$ is always obtained as the residual of the energy budget components, this 'observation-based' balance will always close. In contrast to these 'observation-based' fluxes, CLM simulates $H$ explicitly based on physical laws and calculates $G$ as the residual.

\section{EVAPOTRANSPIRATION}

\section{Reference evapotranspiration ETo}

The Penman-Monteith combination method is used (Allen et al., 1989; Shuttleworth, 1992) to estimate daily reference evapotranspiration ETo, based on meteorological data. The Penman-Monteith equation is based on combining energy balance, heat, and mass transfer approaches to estimate evapotranspiration, as opposed to the purely radiation-based (e.g. Priestley and Taylor, 1972) or temperature-based (e.g. Hargreaves, 1975) approaches. Reference evapotranspiration is a climatic parameter that does not take crop characteristics or soil type into account, but rather calculates the evapotranspiration of a reference crop, given location, meteorological data, and the day of the year (DOY). The reference ETo is the potential or energy limited (also atmosphere limited), so called 'first-stage', evaporation rate. For a hypothetical drought- and disease-free grass crop with a $0.12 \mathrm{~m}$ height, fixed surface resistance of $70 \mathrm{~s} \mathrm{~m}^{-1}$, and an albedo $a$ of 0.23 , the FAO Penman-Monteith equation to calculate daily ETo is (Allen et al., 1998):

$$
\text { ETo }=\frac{0 \cdot 408 \Delta(\operatorname{Rn}-G)+\gamma\left[\frac{900}{T+273}\right] u_{2}\left(e_{\mathrm{s}}-e_{\mathrm{a}}\right)}{\Delta+\gamma\left(1+0 \cdot 34 u_{2}\right)}
$$

with $\mathrm{Rn}$ the net radiation at the crop surface $\left(\mathrm{MJ} \mathrm{m}^{-2}\right.$ day $\left.^{-1}\right), G$ the soil heat flux density $\left(\mathrm{MJ} \mathrm{m}^{-2}\right.$ day $\left.^{-1}\right), T$ the mean daily air temperature at $2 \mathrm{~m}$ height $\left({ }^{\circ} \mathrm{C}\right)$ (which 
can be approximated by $\left(T_{\min }+T_{\max }\right) / 2$ with $T_{\min }$ and $T_{\max }$ the daily minimum and maximum temperature), $u_{2}$ the wind speed at $2 \mathrm{~m}$ height $\left(\mathrm{m} \mathrm{s}^{-1}\right), e_{\mathrm{s}}$ the saturation vapour pressure $(\mathrm{kPa}), e_{\mathrm{a}}$ the actual vapour pressure $(\mathrm{kPa}), \Delta$ the slope vapour pressure curve $\left(\mathrm{kPa}{ }^{\circ} \mathrm{C}^{-1}\right)$, and $\gamma$ the psychrometric constant $\left(\mathrm{kPa}^{\circ} \mathrm{C}^{-1}\right)$. As the magnitude of daily soil heat flux $G$ beneath the reference grass surface is relatively small, it is ignored in the daily ETo calculation. Rn, $e_{\mathrm{s}}, e_{\mathrm{a}}, \gamma$ and $\Delta$ are calculated by

$$
\begin{aligned}
& \mathrm{Rn}=(1-a) \operatorname{Rs}-\sigma \frac{T_{\max }^{4}+T_{\min }^{4}}{2}\left(0 \cdot 34-0 \cdot 14 \sqrt{e_{a}}\right) \\
& \times\left(1.35 \frac{\mathrm{Rs}}{\mathrm{Rso}}-0.35\right) \\
& \text { Rso }=\left(0.75+2 \times 10^{-5} z\right) \mathrm{Ra} \\
& \mathrm{Ra}=(24 \times 60 / \pi) \times 0.0820[1+0.033 \cos (2 \pi \\
& \times \mathrm{DOY} / 365)] \\
& \times\left[\omega_{\mathrm{s}} \times \sin (\text { lat }) \sin (0.409 \sin (2 \pi\right. \\
& \times \text { DOY } / 365-1.39) \text { ) } \\
& +\cos (\text { lat }) \cos (0.409 \sin (2 \pi \times \text { DOY } / 365 \\
& \left.-1.39)) \sin \left(\omega_{\mathrm{s}}\right)\right] \\
& \omega_{\mathrm{s}}=\arccos [-\tan (\text { lat }) \tan (0.409 \sin (2 \pi \\
& \times \text { DOY } / 365-1.39))] \\
& e_{\mathrm{s}}=0.6108\left[\exp \left(\frac{17 \cdot 27 T_{\max }}{T_{\max }+237 \cdot 3}\right)\right. \\
& \left.+\exp \left(\frac{17 \cdot 27 T_{\min }}{T_{\min }+237 \cdot 3}\right)\right] / 2 \\
& e_{\mathrm{a}}=0.6108\left[\exp \left(\frac{17 \cdot 27 T_{\max }}{T_{\max }+237 \cdot 3}\right) \frac{\mathrm{RH}_{\max }}{100}\right. \\
& \left.+\exp \left(\frac{17 \cdot 27 T_{\min }}{T_{\min }+237 \cdot 3}\right) \frac{\mathrm{RH}_{\min }}{100}\right] / 2 \\
& \gamma=\left(0.665 \times 10^{-3}\right) 101.3\left(\frac{293-0.0665 z}{293}\right)^{5.26} \\
& \Delta=\frac{4098\left[0.6108 \times \exp \left(\frac{17 \cdot 27 T}{T+237 \cdot 3}\right)\right]}{(T+237 \cdot 3)^{2}}
\end{aligned}
$$

with Rs the solar shortwave radiation $\left(\mathrm{MJ} \mathrm{m}^{-2} \mathrm{day}^{-1}\right)$, the first and second term of $\mathrm{Rn}$ in Equation (6) corresponding to the net shortwave Rns and longwave Rnl radiation, respectively, Rso the clear-sky solar radiation ( $\mathrm{MJ} \mathrm{m}^{-2} \mathrm{day}^{-1}$ ), $z$ the elevation in (m) a.s.l., Ra the top of the atmosphere radiation ( $\mathrm{MJ} \mathrm{m}^{-2} \mathrm{day}^{-1}$ ) and $\omega_{s}$ sunset hour angle (rad). The vapour pressure is calculated for $T_{\min }$ and $T_{\max }$ individually (instead of the daily average temperature) because of the non-linear relationship between vapour pressure and temperature.

\section{Actual evapotranspiration ETa}

The actual evapotranspiration depends on the vegetation and is limited by soil moisture diffusion. It is therefore also referred to as 'second-stage' evaporation rate. A number of approaches have been proposed to estimate the actual evapotranspiration (e.g. Brutsaert, 1982; Duan and Schaake, 2003). The most straightforward way is to calculate the Penman-Monteith equation for specific crops, under specific soil moisture conditions, but that would require estimates of dynamic resistance and roughness parameters (soil and vegetation characterization).

Here, a data-limited approach is used instead, where a crude estimate of the actual ETa at the SCAN sites is calculated as a fraction of the reference ETo (Equation (5)). The fraction is based on a relationship between observed ETa and calculated ETo at the Goodwin flux tower. Figure 2 shows, per season, the fraction ETa/ETo versus the observed SM for each day over 5 years (2002-2006). Even though it was expected to find a dynamic limiting impact of the available soil moisture on ETa (Gavin and Agnew, 2004), no such evidence can be found across the different seasons and a static temporal mean $\mathrm{ETa} / \mathrm{ETo}=0.624$ is determined as a general stress coefficient to convert the site-specific ETo to ETa at all SCAN sites. The stress factor includes any actual deviation from the above assumed parameterization for ETo and most likely accounts for the specific vegetation and soil types here (the latter being different from the dynamic soil moisture availability). Within the observed SM range, no dynamic SM limiting impact on ETa can be identified in the winter, spring and fall months. This confirms the finding by Dirmeyer et al. (2009) that, in this region, ETa controls SM, and water is not a dynamic limiting factor on ETa, while energy is the main limiting factor. Some soil moisture effect on ETa can be observed in the summer months, where some years show a decrease in ETa with limiting SM, but in other years this is not observed. The model results will further support this observation.

In contrast to the above ETa estimation for the 'observed' budgets, the CLM calculates the evapotranspiration and sensible heat for a simulated soil, vegetation and air water content and temperature, while taking
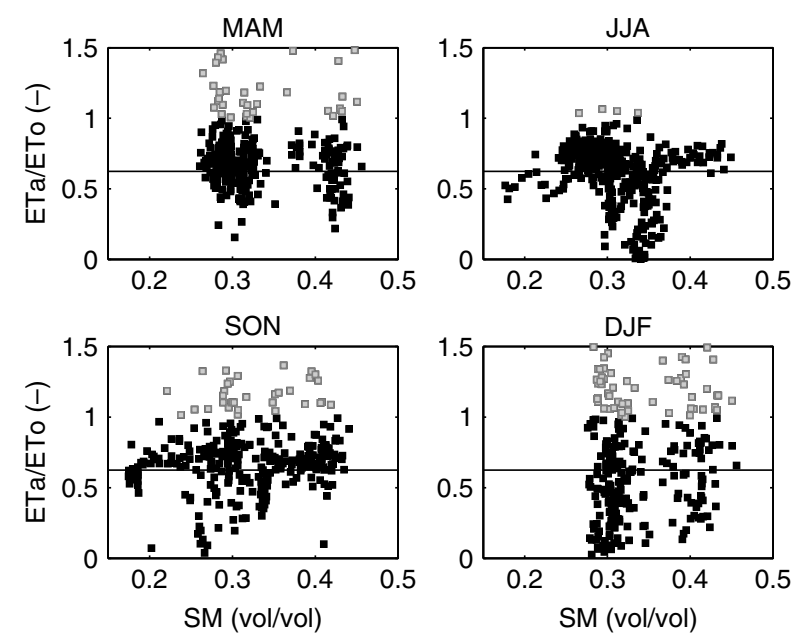

Figure 2. Relationship between daily observed ETa/ETo and root zone soil moisture SM at the Goodwin tower location in four seasons over the years 2002-2006. Each point represents 1 day. Possibly erroneous $\mathrm{ETa} / \mathrm{ET}$ fractions larger than 1 (grey points) are excluded from the temporal mean (line, mean over all seasons) calculation 
into account several dynamic resistance factors. ETa is obtained as a combination of evapotranspiration fluxes from dry and wet foliage and ground evaporation. The relationship between simulated SM and ETa/ETo will be shown in CLM3.5 Evaluation section.

\section{RESULTS}

\section{Observed water budget components}

Local site water budget components. Before focusing on the regional averaged water balance, the individual 16 sites and their observed temporal characteristics are studied to determine the spatial variability of water balance components. Table II summarizes the daily temporal mean and range (maximum-minimum value over the studied period) of the different variables for each site.

Table II. Daily observed $P$, ETa, SM and NDVI means $(m)$ and ranges $(d=\max -\min )$ at each SCAN site over the study period January 2002-May 2008

\begin{tabular}{|c|c|c|c|c|c|c|c|c|}
\hline \multirow[t]{2}{*}{ Site } & \multicolumn{2}{|c|}{$\begin{array}{c}\text { SM } \\
(\mathrm{mm})\end{array}$} & \multicolumn{2}{|c|}{$\begin{array}{c}P \\
\left(\mathrm{~mm} \mathrm{day}^{-1}\right)\end{array}$} & \multicolumn{2}{|c|}{$\begin{array}{c}\text { ETa } \\
\left(\mathrm{mm} \mathrm{day}^{-1}\right)\end{array}$} & \multicolumn{2}{|c|}{$\begin{array}{c}\text { NDVI } \\
(-)\end{array}$} \\
\hline & $m$ & $d$ & $m$ & $d$ & $m$ & $d$ & $m$ & $d$ \\
\hline 91 & $109 \cdot 66$ & & & 96.52 & 2.02 & $4 \cdot 29$ & 0.46 & 0.46 \\
\hline 30 & 8 & & & 16 & & & 0.44 & \\
\hline 84 & 122. & & & & $\pi$ & 4.5 & 0.51 & 0.62 \\
\hline 085 & $126 \cdot 02$ & 8 & $2 \cdot 61$ & 86 & $2 \cdot 02$ & $5 \cdot 50$ & 0.48 & $0 \cdot 70$ \\
\hline 110 & 138.84 & $49 \cdot 76$ & $3 \cdot 19$ & 135. & $2 \cdot 18$ & 4.88 & 0.75 & 0.50 \\
\hline 046 & $135 \cdot 37$ & $75 \cdot 59$ & $3 \cdot 12$ & $163 \cdot 3$ & $2 \cdot 18$ & $5 \cdot 19$ & 0.48 & 0.68 \\
\hline 087 & $136 \cdot 41$ & $45 \cdot 75$ & $3 \cdot 28$ & $136 \cdot 9$ & $2 \cdot 15$ & 4.92 & 0.44 & 0.69 \\
\hline 032 & 138.99 & $65 \cdot 80$ & 2.94 & $106 \cdot 43$ & $2 \cdot 20$ & $5 \cdot 52$ & 0.46 & 0.74 \\
\hline 034 & $126 \cdot 68$ & 71.40 & 2.96 & $121 \cdot 1$ & $2 \cdot 07$ & 5.00 & 0.47 & 0.64 \\
\hline 2033 & $135 \cdot 31$ & $36 \cdot 26$ & $3 \cdot 17$ & $232 \cdot 8$ & $2 \cdot 12$ & 4.92 & 0.47 & 0.63 \\
\hline 2070 & $123 \cdot 07$ & $46 \cdot 7$ & $2 \cdot 74$ & $119 ?$ & $2 \cdot 11$ & $5 \cdot 13$ & 0.40 & 0.75 \\
\hline 2025 & $108 \cdot 13$ & 94.96 & $2 \cdot 76$ & 169.9 & $2 \cdot 04$ & 5.48 & $0 \cdot 60$ & 0.53 \\
\hline 2024 & $126 \cdot \xi$ & & 2.73 & & $2 \cdot 06$ & 5.46 & 0.68 & 0.46 \\
\hline 2086 & 113.73 & & 2.97 & 155.79 & 2.02 & 4.79 & 0.53 & 0.73 \\
\hline 2035 & 134.05 & & $3 \cdot 23$ & 128. & 1.96 & 4.85 & 0.53 & 0.68 \\
\hline 2109 & 57.44 & $99 \cdot 28$ & $3 \cdot 24$ & 87.85 & $2 \cdot 12$ & $5 \cdot 17$ & 0.40 & 0.74 \\
\hline
\end{tabular}

For the area-integrated discharge $D$, the temporal mean and range are 1.26 and $15.19 \mathrm{~mm} \mathrm{day}^{-1}$, respectively.

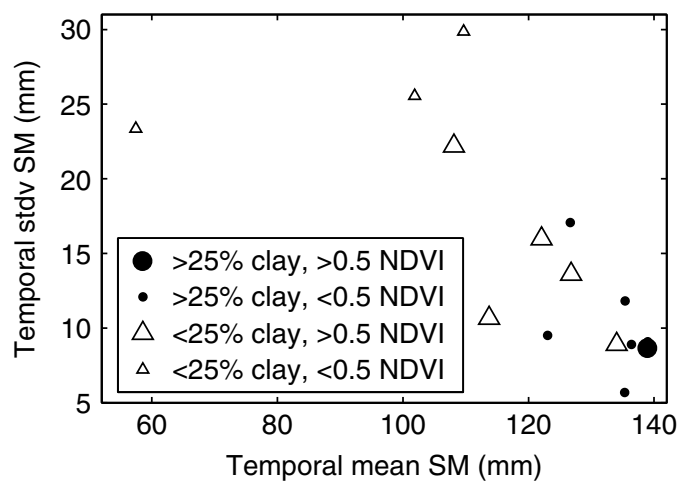

Note that these statistics depend on the study period duration (Duan and Schaake, 2003). Figure 3 shows the temporal (climatological) mean and standard deviation in daily SM and ETa for different classes of texture and NDVI at different individual locations and Table III lists some corresponding correlation coefficients. The daily SM variability decreases with higher mean SM, which is related with higher clay contents $(r=-0.57$ and 0.65 between clay content and temporal standard deviation and mean SM, respectively). The storage range is typically higher where clay is limited, i.e. land systems with a more sandy texture are more responsive or allow propagation of higher frequency signal inputs. Conversely, regions with higher clay levels retain more constant moisture levels, despite changes in meteorological factors, i.e. there is a slow system response. Likewise, the time series correlation between the SM evolution at each site and $D$ is found to be high (not shown) for more sandy textures, because clay has a higher water holding capacity and it smooths both the storage and the outflow response to incoming precipitation. NDVI is not correlated to the soil texture (not shown) and has a lower variability at locations with high NDVI (NDVI is a bounded variable with decreasing variability for temporal means near the limits), which typically corresponds to more permanent vegetation cover, such as forest, woodland or wooded grassland. In contrast to the findings of Duan and Schaake (2003) for the Arkansas-Red River basin, texture is a much better storage range indicator than vegetation. The actual

Table III. Linear correlation coefficients between observed temporal means $m$ and standard deviations $s t d v$ in daily $P(\mathrm{~mm}$ day $\left.^{-1}\right)$, ETa $\left(\mathrm{mm} \mathrm{day}^{-1}\right), \mathrm{SM}(\mathrm{mm})$ and NDVI $(-)$ and local (SCAN) texture (\% clay) at 16 SCAN sites

\begin{tabular}{lcrr}
\hline & Clay & $m$ NDVI & $s t d v$ NDVI \\
\hline$m$ SM & $0.65^{*}$ & 0.32 & -0.08 \\
$m$ ETa & $0.80^{*}$ & -0.02 & 0.28 \\
$m$ P & 0.46 & 0.03 & 0.39 \\
$s t d v$ SM & $-0.57^{*}$ & -0.20 & -0.44 \\
$s t d v$ ETa & 0.28 & -0.33 & 0.09 \\
$s t d v$ P & 0.36 & 0.02 & 0.15
\end{tabular}

The significant $(p=0.05)$ correlations are indicated with $*$.

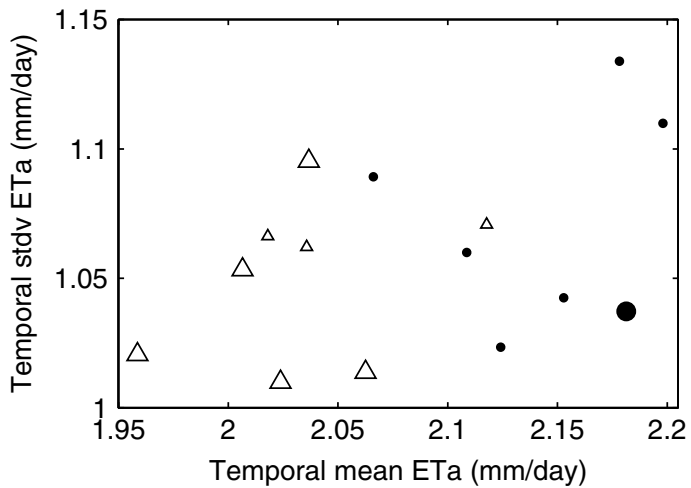

Figure 3. Relationship between temporal mean and standard deviation (SD) in daily observed soil moisture SM and evapotranspiration ETa at 15 individual sites, with indication of SCAN clay content $(\%)$ (one of the 16 sites has no SCAN texture reported) and local point temporal mean NDVI (-) 
evapotranspiration ETa is higher for high clay content sites $(r=0.80)$, which are typically wetter. However, because the ETa is really only a constant fraction of the climatic ETo, this means that the microclimate (temperature, humidity) over wetter clay soils results in higher ETo values, i.e. we observe the effect of the microclimate on ETo (and hence ETa), which is not to be confused with the theoretical (but not included here) dynamic impact of soil moisture on ETa.

Regional water budget components. Regional averaged observed time series are studied to investigate the internal consistency of the observed water budget components and to detect characterizing trends for the studied points in the Lower Mississippi Basin. All regional averages are a simple arithmetic mean of the observed values at each of the 16 SCAN stations. It should be recalled that missing precipitation data have been filled in through a regression with a station that showed the highest correlation during the overlapped period of data availability. Figure 4 shows spatially averaged time series of total monthly precipitation $P$, drainage $D$, actual evapotranspiration ETa and root-zone soil water storage SM (water amounts, $\mathrm{mm}$ ), as well as the spatial standard deviation (except for the mean unit area discharge). Additionally, the evolution of the NDVI is shown. There is a clear seasonal pattern in ETa and NDVI, while $P$, and hence $D$ and SM, are more driven by short term stochastic processes. The discharge $D$ shows roughly a similar pattern as the precipitation $P$, but some discrepancies appear, because (i) the 16-station spatial mean $P$ is based on individual point observations, while the averaged $D$ per unit area is a basin-integrated measurement, (ii) the first 2 years have many missing $P$ data and interpolation may lead to underestimation in 2002, where observed $D$ exceeds incoming $P$, and (iii) possible irrigation is not taken into account. This input bias causes an internal inconsistency in the observed water balance. Furthermore, the precipitation time series recorded at SCAN sites do not take into account some irrigation that may affect the basin-integrated $D$. Also, this area contains some wetlands, lakes and ponds and may influence the basin-integrated $D$. High monthly total $P$ amounts correspond to an increased spatial $P$ variability. Since $P$ is bounded at the low end, a small variability is expected for small mean values. The land acts as a low pass filter on the $P$ time series to yield a smooth SM storage evolution. The spatial SM variability is slightly higher for low spatial mean values, because the spatial texture variability will determine more of the SM variability under dry circumstances than in wet situations where a larger range of texture classes can retain water. The spatial NDVI variability is higher in the winter than in the summer, because some crop regions become vegetation free (bare soil), while others have permanent vegetation cover.

To study possible memory processes that may make the system predictable, the anomaly auto-correlation for different time lags is plotted in Figure 5 (period January 2002-May 2008), both for the daily and monthly areaaveraged observations. The anomalies are calculated as the difference between the actual daily or monthly value and the 6-year average (2002-2007) of the variable at that particular day or month. For monthly data, SM anomalies have a 2-month auto-correlation length (i.e.
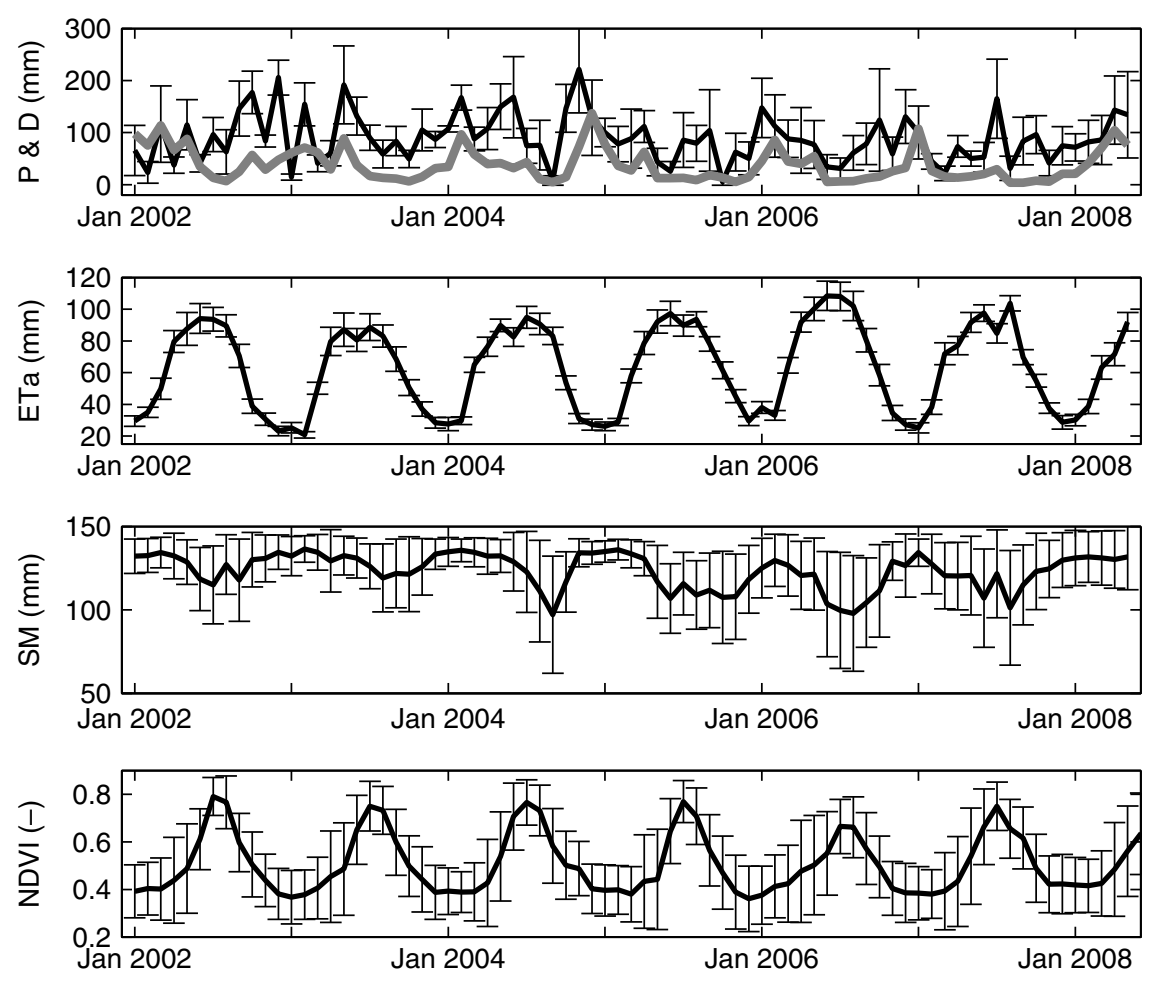

Figure 4. Spatial mean \pm 1 standard deviation (regional average over 16 SCAN sites) of monthly observed total precipitation $P$, evapotranspiration ETa, average soil moisture SM and NDVI from January 2002 through May 2008. The spatial mean unit area discharge $D$ is shown with a grey line 


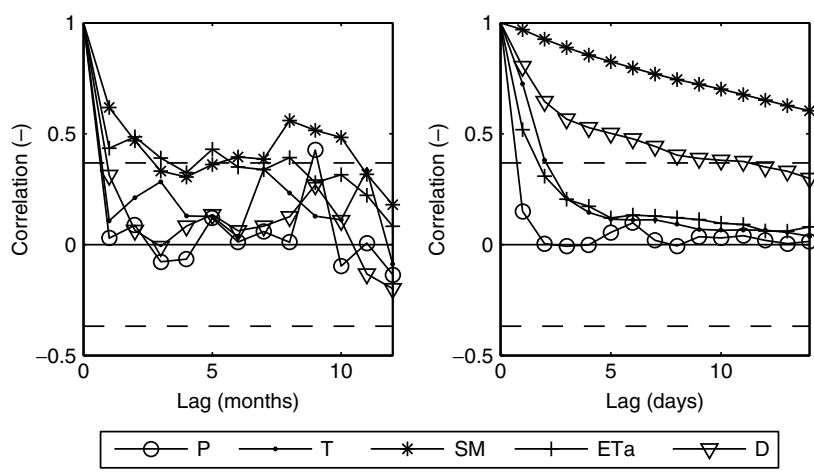

Figure 5. Anomaly auto-correlation in monthly and daily regional averaged precipitation $P$, temperature $T$, soil moisture SM, actual evapotranspiration ETa and discharge $D$ time series, observed over the period January 2002-May 2008. The dashed lines represent $\pm 1 / e$ where 1/e is reached). Precipitation $P$, air temperature $T$, and discharge $D$ anomalies have a correlation length of less than a month, while ETa has a somewhat similar correlation pattern as SM. At a daily scale, the autocorrelation length in $P$ is again negligible, for $T$ and ETa it is a couple of days and for SM and $D$ anomalies the correlation scale reaches over 2 weeks and even beyond that for SM. Since SM is a main state variable of the hydrologic system, its longer correlation length is beneficial for the land system predictability.

The cross-correlation between the area-averaged variables gives further insight in how the different variables are related to each other (Figure 6). The highest crosscorrelation between monthly SM and $P$ anomalies is at a zero lag, while for daily data the maximum is found at a 1-day lag, with continuing high cross-correlations for
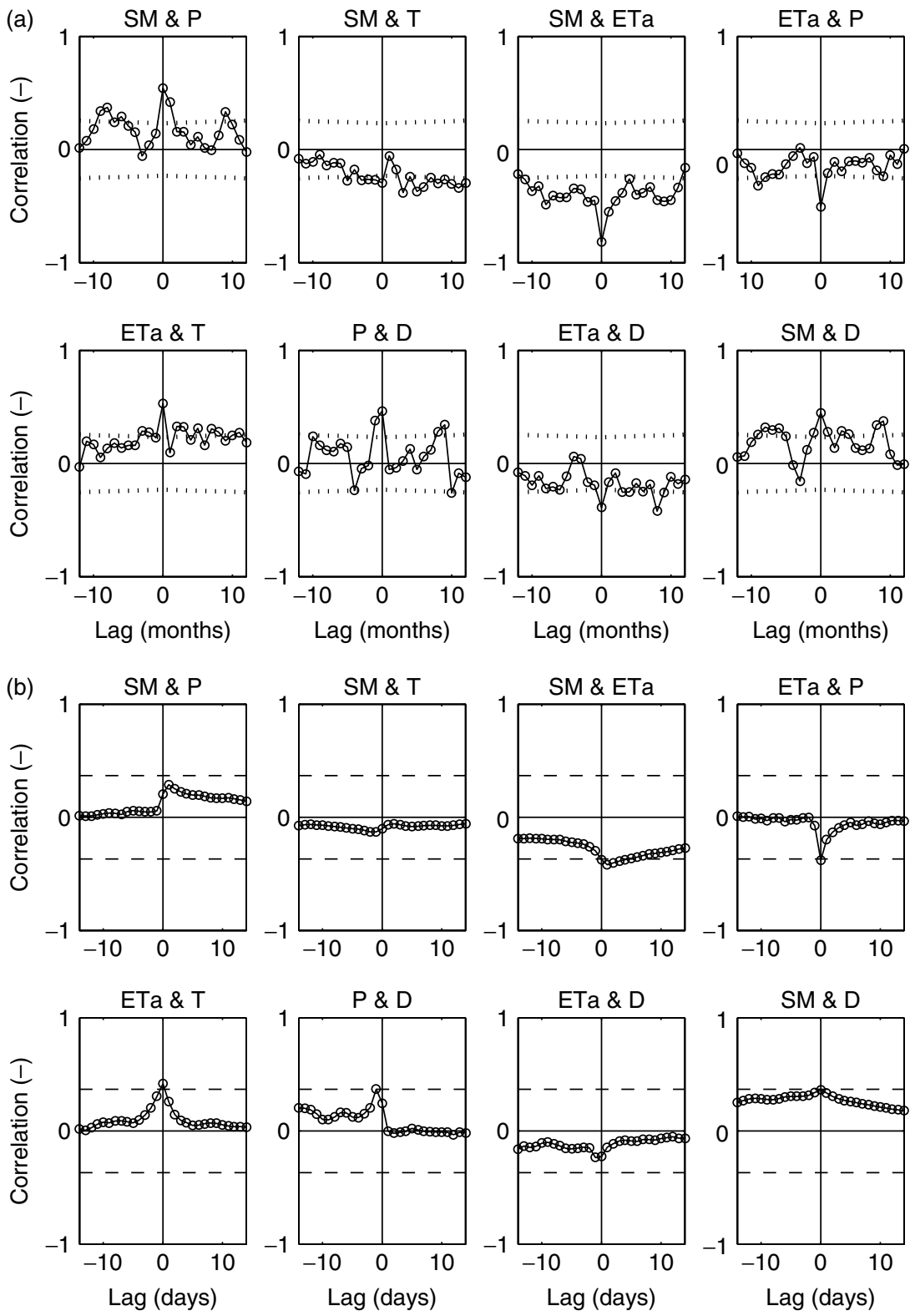

Figure 6. Anomaly cross-correlation in observed (a) monthly and (b) daily regional precipitation $P$, soil moisture SM, temperature $T$ and discharge $D$ time series for the period January 2002-May 2008. A positive lag means that a future part of the first listed variable's time series is compared to a historical part in the second listed variable. For the monthly plots, the significant $(p=0.05)$ correlation levels are indicated by the dotted line. For the daily plots, the dashed lines represent $\pm 1 / e$ and correlations are significant $(p=0.05)$ for absolute values greater than $0 \cdot 04$ 
several days. A similar correlation pattern is found for $P$ and $D$ with a maximum correlation at a zero monthly lag, but at the daily scale several days of correlations can be observed with $D$ lagging behind $P$. Both the crosscorrelation between SM and $P$, and $P$ and $D$ anomalies reflect the causality of the system. SM and ETa (and temperature $T$ ) are negatively correlated. The curves for daily data show a maintained absolute higher SM and ETa cross-correlation for positive lags. This means that future SM is correlated to past ETa, or in other words that ETa determines the SM rather than vice versa. Evidently, this is also a consequence of the ETa calculation, which is a scaled ETo without any account for dynamic SM changes. The highly significant negative correlation between SM and ETa again reflects the dominating control of ETa over SM in this region, because of energy limiting conditions and abundant precipitation (and hence no soil moisture shortage) in winter, spring and fall (Dirmeyer et al., 2009).
Regional water budget partitioning. The partitioning of monthly observed incoming $P$ into $\Delta S$, ETa and $D$ is shown in Figure 7a. Note that at the monthly scale, ETa is always positive (dew is limited) and can exceed $P$, which results in a negative $\Delta S$. The areaaveraged ETa flux has the largest fractions in the summer, while $D$ is the major outgoing fraction in the winter. Consequently, the runoff coefficients vary seasonally, with higher values in winter than in summer. The ratios of the total annual discharge to the total precipitation (runoff coefficient) for 2002, 2003, 2004, 2005, 2006 and 2007 are $0.56,0.42,0.41,0.36,0.36$ and 0.33 , respectively. The high runoff coefficient in the first year is not realistic and due to underestimated precipitation (or possibly unobserved irrigation). Furthermore, high summer ETa is often not balanced with storage loss (ETa $+D+\Delta S>P$ ), which can be due to the rough estimate of ETa, but surely also indicates an incomplete storage measurement: no groundwater or canopy water is
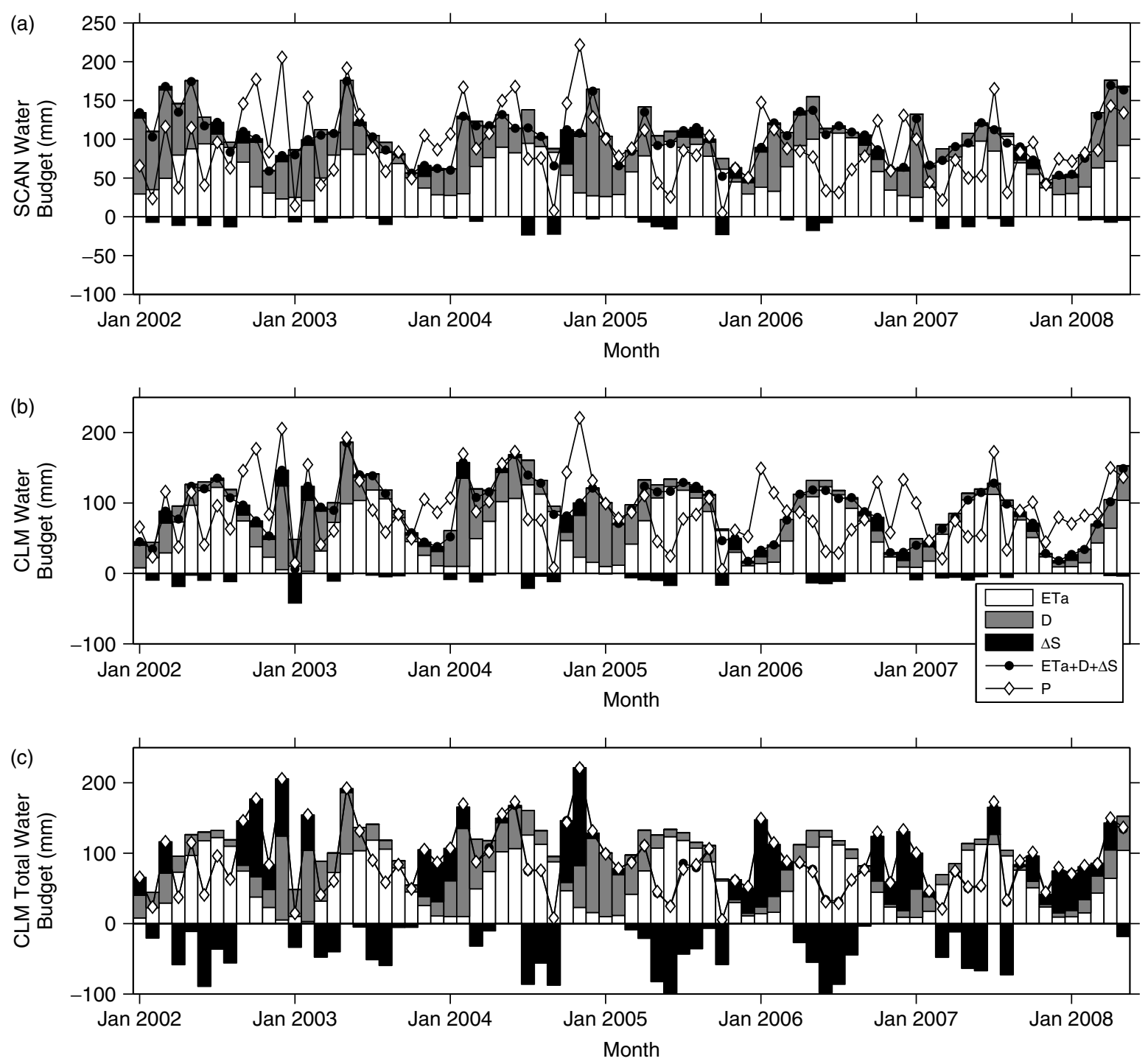

Figure 7. Evolution of the monthly regional averaged (16 SCAN sites) (a) observed and (b, c) simulated water budget, with (b) showing root zone storage only in $\Delta \mathrm{S}$, as in the observations, while (c) takes into account all simulated storage components in $\Delta S$. Subplot (c) has a perfect water budget closure and hence, ETa $+D+\Delta S$ and $P$ are overlapping. The model results are FAO texture-based simulations. All symbols are clarified in 
observed to account for the water balance error. In winter months, there is some water missing from the balance, again because the ETa is only roughly estimated and the storage is not fully observed, i.e. snow and ice are not included. In summary, the water budget is not closed when comparing independent measurements and a more complete or correct measurement of the water storage, ETa and precipitation is needed to obtain closure.

Interannual comparison of water budget components. Comparison of the monthly water balance components within each season and over the multiple years allows us to study how water is partitioned under different conditions as well as to identify extreme dry or wet periods. The interannual anomaly correlations between the mean monthly SM and P-ETa, $D, T$ and NDVI over the 6-year study period and per season (18 data points per correlation value: 6 years $\times 3$ months) are shown in Figure 8 . The negative correlation between SM and $T$ anomalies in the summer is underlying earlier findings by Bonan and Stillwell-Soller (1998) that soil moisture feedbacks eventually amplify the severity of floods and droughts in this region, which is a characteristic for the Mississippi Basin. The difference between $P$ and ETa (P-ETa) and the drainage $D$ anomalies show a significant positive correlation with SM anomalies in all seasons, except in the winter. The NDVI anomalies are highly correlated with SM anomalies in summer and fall, but negligible in spring and winter. Likewise, a high negative anomaly correlation is found between NDVI and ETa in summer and fall. This may suggest that NDVI is a valid indicator of soil moisture and vegetation stress (hydrological and agricultural drought) in this area during summer and early fall months.

\section{Observed energy budget components}

The individual components of the energy budget are not measured independently at the SCAN sites, but

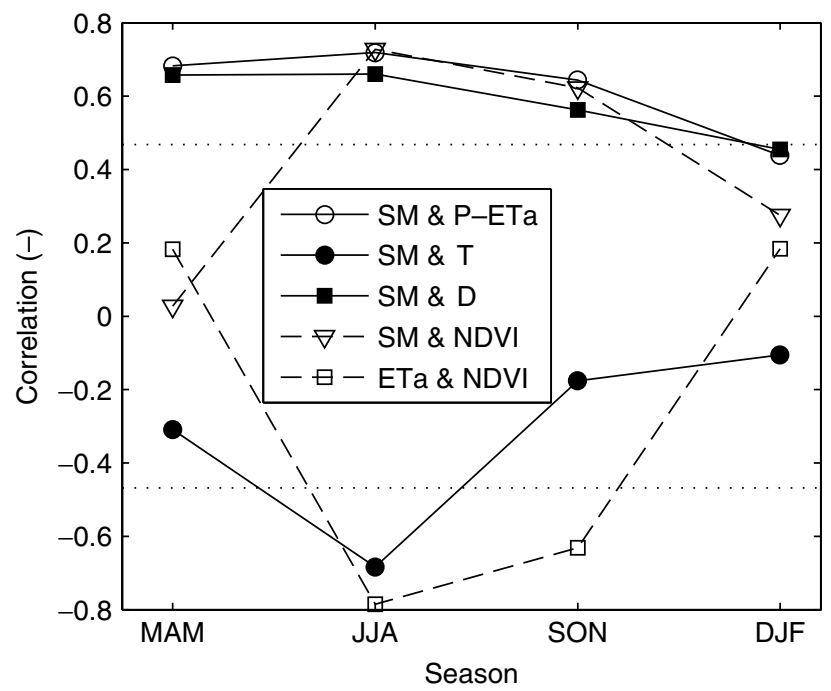

Figure 8. Interannual anomaly correlation between observed regional averaged monthly SM and P-ETa, $T, D$, ETa and NDVI, calculated over 6 complete years from March 2002 to March 2008. The dotted lines show the significant correlation level $(p=0.05)$ derived through simple equations. Hence the monthly $\mathrm{Rn}$ (Equation (6)), $G$ (Equation (4)), $\lambda E T a$ (see section on Actual Evapotranspiration ETa) and $H$ (residual) time series close the water balance. Figure 9 a shows that $\lambda E T a$ consumes most of the incoming energy, most so in the winter months. The $\lambda E$ Ta rate is clearly limited by the available incoming energy, as discussed above. In some summer months, the available energy is most likely not maximally used by $\lambda \mathrm{ETa}$, because soil and vegetation characteristics are limiting. The monthly ground heat flux $G$ is incoming for the first half of the year and outgoing from August onwards, when the sum of $\lambda \mathrm{ETa}$ and $H$ exceeds the decreasing $\mathrm{Rn}$. The Rn, ETa and $H$ have a similar seasonal pattern, reaching low values during the winter half of the year, but remaining positive at the monthly scale.

\section{CLM3.5 evaluation}

Both the CLM simulations with local SCAN observed and FAO-derived soil textures are compared to the observations (or observation-based values), after aggregation to daily and monthly values. Before merging all point simulations into a regional average, we discuss the performance at individual SCAN locations. Figure 10 evaluates the temporal daily mean and standard deviation in SM and ETa at the individual SCAN locations against observations. The FAO-based SM simulations show a slightly better agreement with observed mean and standard deviation in SM than the local SCAN texture-based simulations. Simulations with FAO textures are generally drier than the observations, while those with local SCAN textures are wetter. The simulated mean ETa agrees with the observations, but the simulated temporal variability is larger. The ETa is only marginally affected by the soil texture choice, while the SM is different. This suggests that the simulated ETa may not be very sensitive to SM differences in this area, as was earlier suggested by Goodwin tower observations in Figure 2, and which confirmed the expectations for non-water-limited areas (Dirmeyer et al., 2009). The very low SM sensitivity of ETa over this area suggests a priori that parameter or state updating with SM data only may not substantially affect ETa in this area, even though improved ETa estimation is a major objective of hydrologic SM data-model fusion. Constraining the land surface temperature may be more important in order to enhance the ETa estimation.

Time series of monthly regional averaged (16 SCAN point simulations) SM, ETa, $D, H, G$ and Rn are shown in Figure 11. The root-mean-square-error (RMSE) and the correlation between daily or monthly observed and simulated regional averaged SM, ETa, $D, H, G$ and Rn over the 6-year period are listed in Table IV. Even though the time correlation between observed and simulated time series are large, the simulated SM dynamics differ from those observed and are affected by the texture choice, as is clear from the RMSE and Figure 11. Model and parameter deficiencies limit our ability to correctly match the simulated and observed soil moisture climatologies 

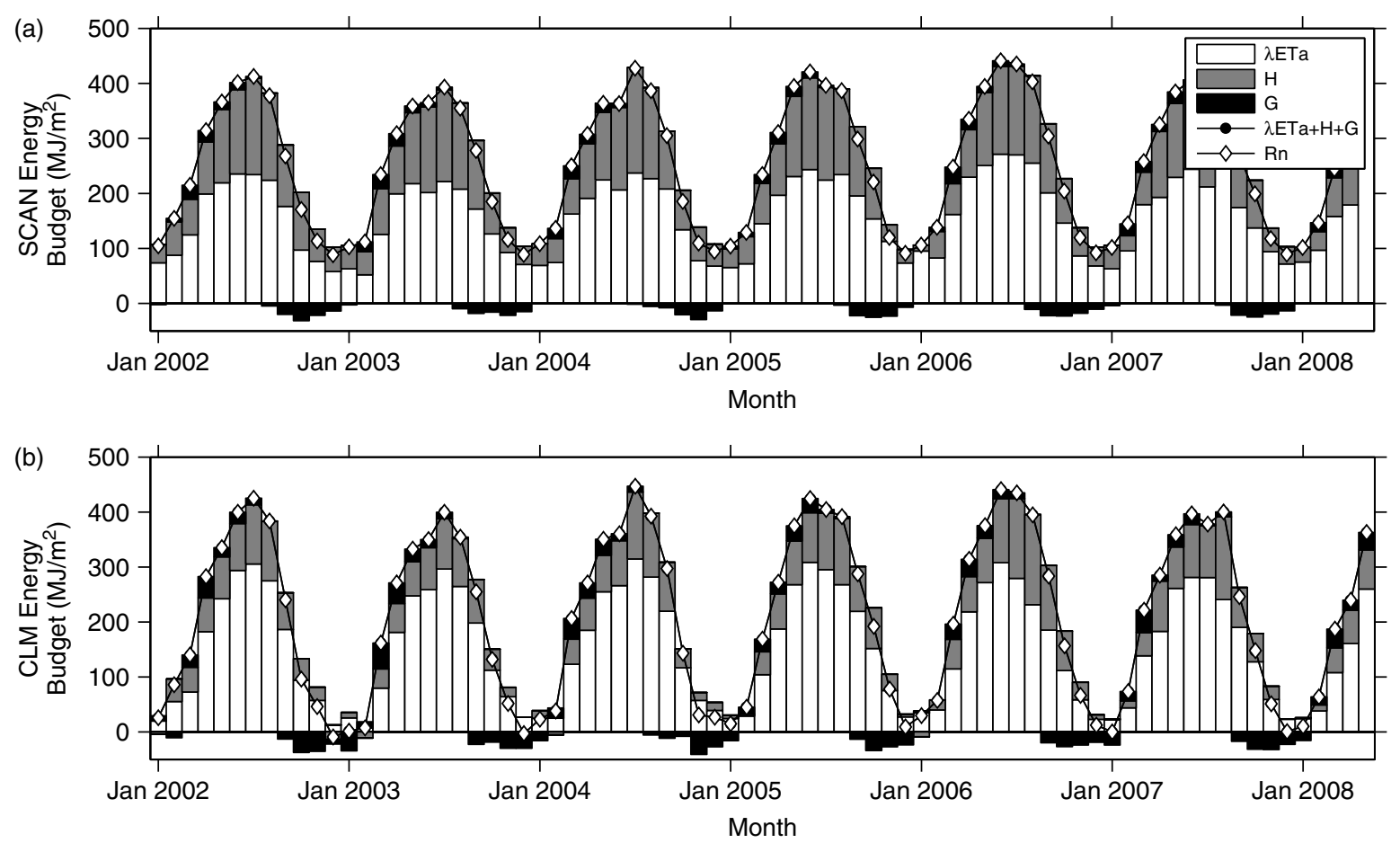

Figure 9. Evolution of the monthly regional averaged (16 SCAN sites) (a) observed and (b) simulated energy budget components. The model results are FAO texture-based simulations. All symbols are clarified in the text. Both the observation-based and simulated energy budget close by design, causing $\lambda \mathrm{ETa}+H+G$ and $\mathrm{Rn}$ to overlap
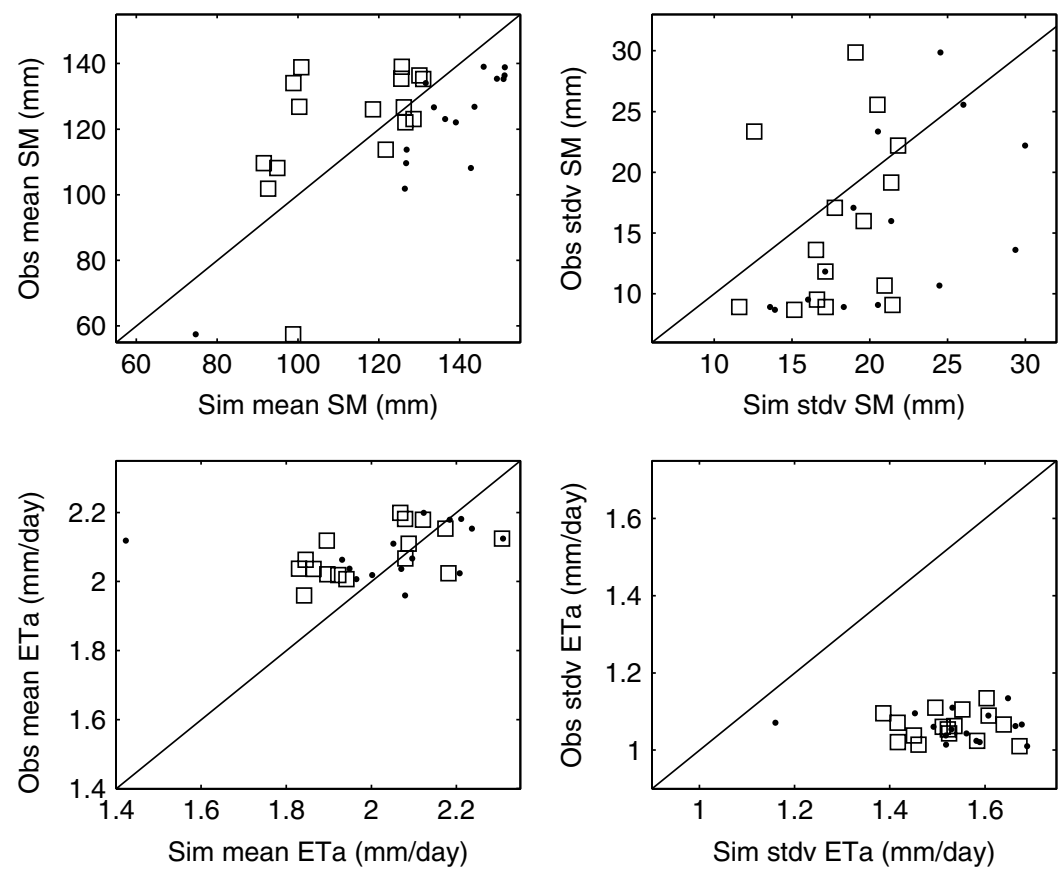

Figure 10. Comparison of temporal mean and standard deviation (SD) in hourly observed and simulated $(\cdot=\mathrm{SCAN}, \square=$ FAO) soil moisture SM and evapotranspiration ETa for the period January 2002-May 2008. Each point reflects one SCAN site location

(Zeng and Decker, 2009). The simulations with FAO texture show a significant improvement in SM time correlations (and a lower RMSE) over simulations with locally observed SCAN texture. This could possibly be explained by a compensation of model errors for some simulated profiles. As an approximation of the simulated unit area discharge $D$, we sum the surface runoff and subsurface drainage without any routing, which could be justified for monthly data $(r=0.67$ between observations and simulations), when the travel time is less than a month. The latter is supported by the maximum correlation between $P$ and $D$ at a zeromonth lag (Figure 6), but this latter argument may not be exactly correct when the water periodically flows through wetlands, ponds or reservoirs in this area. At the daily scale, non-routed $D$ is obviously not a good 

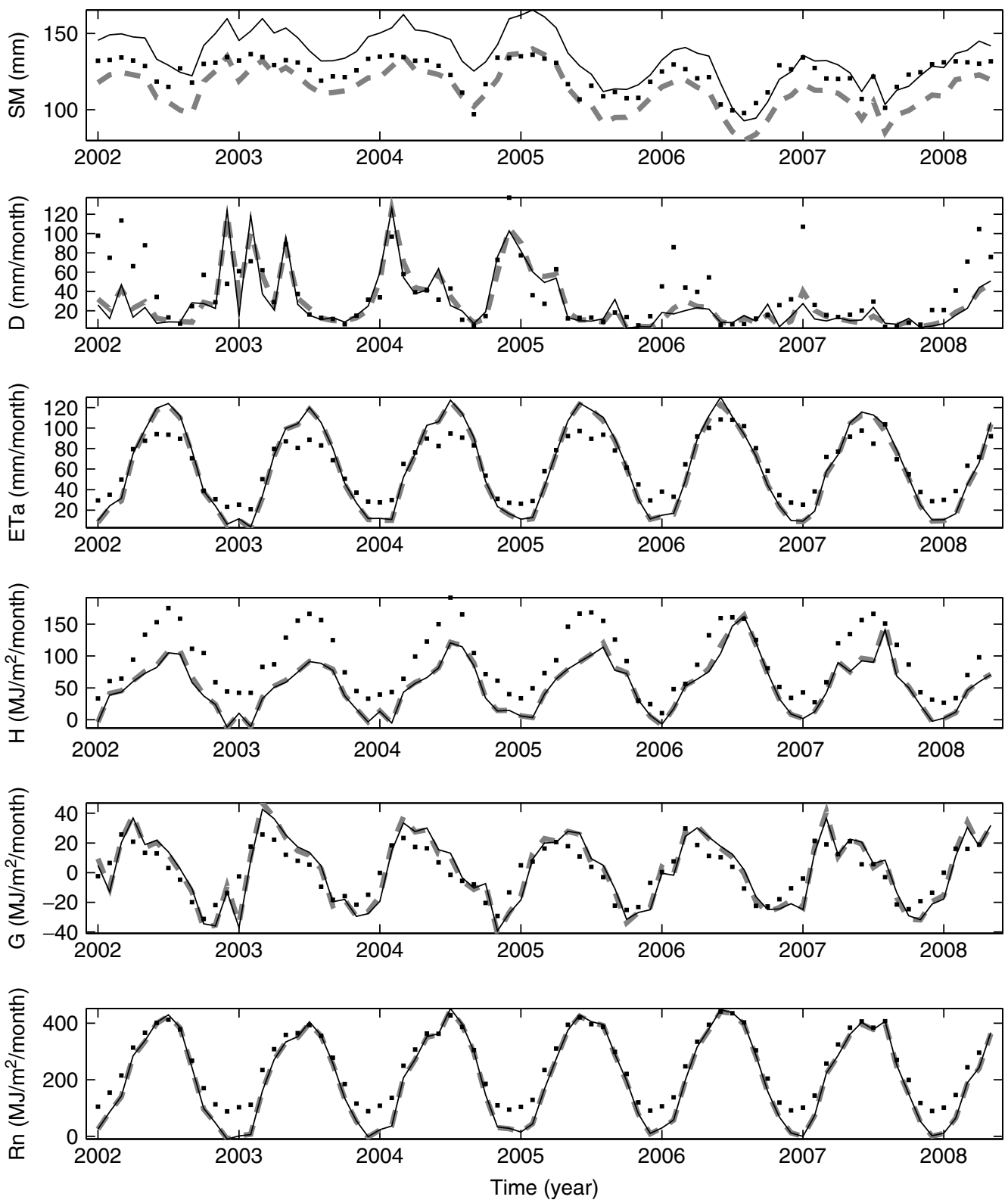

Figure 11. Monthly regional averaged (black line = SCAN, grey dashed = FAO) simulated and (dots) observed, or observation-derived, soil moisture $\mathrm{SM}$, runoff and drainage $D$, evapotranspiration ETa, sensible heat flux $H$, ground heat flux $G$ and net absorbed radiation Rn

representation of the actual observed discharge $(r=$ 0.46). The simulated sensible heat flux $H$ and net radiation $\mathrm{Rn}$ have a lower value and the $\mathrm{Rn}$ has a higher temporal variability than the observations (Figure 11), because it decreases to lower values in the winter. Yet the correlation coefficient between observed and simulated $\mathrm{Rn}$ is nearly 1 (because the time series are dominated by the annual cycle), which indicates a tilt in the regression slope. The difference between simulated and observationbased Rn during a few winter months is mainly due to differences in the net longwave radiation Rnl simulation (air and soil temperature-based). The simulated Rnl is higher than observed (mainly at low Rnl in winter months), causing a lower simulated $\mathrm{Rn}$ (=Rns-Rnl) and corresponding $H$ than observed. Monthly $G$ is approximated based on air temperature differences for the observation-based budget, while it is the residual component in the CLM simulations, but both are very similar.

Table IV again highlights how texture-based differences in SM have almost no impact on the validation measures for ETa and most other energy budget components (except maybe $G$ ), because this area falls in a regime where ETa is controlling SM and soil hydraulic parameters are not affecting ETa. However, $D$ shows some SM sensitivity, and calibration or state updating using SM observations will improve $D$ estimates, which supports this common practice in hydrology. The limited impact of simulated SM on ETa is further explained in Figure 12, which shows ETa/ETo versus SM for the regionally averaged time series and per season. Only the summer months show some dynamic impact of SM on ETa/ETo. The highest fractions appear in the summer, because of active vegetation. The lowest ETa/ETo 
Table IV. Evaluation (root mean square error, RMSE and correlation, $R$ ) of regional averaged FAO texture-based and SCAN texture-based CLM simulations with observations or observation-derived water and energy budget variables

\begin{tabular}{|c|c|c|c|c|c|}
\hline & \multicolumn{2}{|c|}{ FAO } & \multicolumn{2}{|c|}{ SCAN } & \multirow[t]{2}{*}{$R$ diff } \\
\hline & RMSE & $R$ & RMSE & $R$ & \\
\hline Daily SM (mm) & $13 \cdot 31$ & 0.83 & $15 \cdot 57$ & $0 \cdot 80$ & * \\
\hline$D\left(\mathrm{~mm} \mathrm{~m}^{-2}\right.$ day $\left.^{-1}\right)$ & 1.78 & 0.46 & $2 \cdot 57$ & $0 \cdot 38$ & $*$ \\
\hline ETa $\left(\mathrm{MJ} \mathrm{m}^{-2}\right.$ day $\left.^{-1}\right)$ & 0.64 & 0.93 & $0 \cdot 64$ & 0.93 & \\
\hline$H\left(\mathrm{MJ} \mathrm{m}^{-2}\right.$ day $\left.^{-1}\right)$ & 8.73 & $0 \cdot 88$ & $8 \cdot 78$ & $0 \cdot 88$ & \\
\hline$G\left(\mathrm{MJ} \mathrm{m}^{-2}\right.$ day $\left.^{-1}\right)$ & 1.74 & N/A & 1.68 & N/A & \\
\hline $\operatorname{Rn}\left(\mathrm{MJ} \mathrm{m}^{-2}\right.$ day $\left.^{-1}\right)$ & $2 \cdot 23$ & 0.98 & $2 \cdot 22$ & 0.98 & \\
\hline Monthly SM (mm) & $12 \cdot 33$ & $0 \cdot 87$ & 14.96 & $0 \cdot 84$ & * \\
\hline$D\left(\mathrm{~mm} \mathrm{~m}^{-2} \mathrm{month}^{-1}\right)$ & $25 \cdot 88$ & 0.67 & $28 \cdot 40$ & $0 \cdot 61$ & * \\
\hline $\mathrm{ETa}\left(\mathrm{MJ} \mathrm{m} \mathrm{month}^{-1}\right)$ & $16 \cdot 28$ & 0.97 & $16 \cdot 24$ & 0.97 & \\
\hline$H\left(\mathrm{MJ} \mathrm{m}^{-2}\right.$ month $\left.^{-1}\right)$ & $43 \cdot 24$ & 0.91 & $44 \cdot 61$ & 0.91 & \\
\hline$G\left(\mathrm{MJ} \mathrm{m}^{-2}\right.$ month $\left.^{-1}\right)$ & $10 \cdot 84$ & 0.90 & $11 \cdot 34$ & $0 \cdot 87$ & * \\
\hline $\operatorname{Rn}\left(\mathrm{MJ} \mathrm{m}^{-2}\right.$ month $\left.^{-1}\right)$ & $55 \cdot 20$ & 0.99 & $54 \cdot 41$ & 0.99 & \\
\hline
\end{tabular}

The observed $G$ is assumed to be constant $0 \mathrm{MJ} \mathrm{m}^{-2}$ day $^{-1}$ at the daily scale. An asterix in the last column indicates a statistical significant $R$ difference ( $p=0.05$ ) between the simulations with different texture specifications.
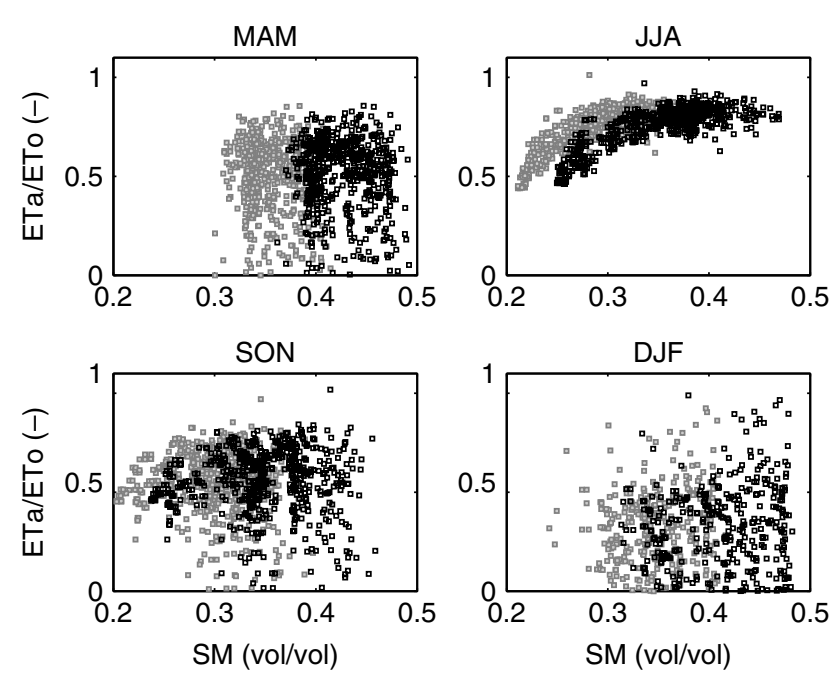

Figure 12. Relationship between regional averaged daily simulated $\mathrm{ETa} / \mathrm{ETo}$ and simulated root zone soil moisture SM (black = SCAN, gray $=$ FAO) in four seasons over the years 2002-2008. Each point represents 1 day

fractions are found in the winter time because no vegetation transpiration contributes to ETa, while ETo is overestimated, because it is calculated for active vegetation.

Figure $7 b$ and $c$ show simulated water budgets. Any discrepancy between the simulated water budget partitioning and the observed one in Figure $7 \mathrm{a}$ is entirely due to the nature versus model-based partitioning of outgoing fluxes and state changes. The relative partitioning of water is very similar for both FAO and SCAN soil texture (only FAO is shown) and close to the observed one, with outgoing ETa taking the largest fraction of incoming $P$ during vegetation growth. The simulated $D$ is largely underestimated in 2002 and from 2006 onwards. The underestimation can be attributed to precipitation input bias. From 2006 onwards, we observe a decrease in simulated SM (Figure 11), along with a decrease in $D$, while the observations do not show this trend. A possible reason may be that irrigation adds to the observed $D$ and SM. Even though there is some discrepancy in the mean SM climatology, the storage changes are very similar for both observed and simulated root zone soil moisture. The simulated water balance does not close (Figure $7 \mathrm{~b}$ ) when considering only the simulated root-zone soil moisture (in correspondence with the observations). This indicates the deficiencies in our collected observations for balance closure. With inclusion of simulated soil ice, canopy water, unconfined water and snow changes (Figure 7c), a perfect agreement between $P$ and ETa $+D+\Delta S$ is assured. More specifically, the positive $\Delta S$ changes added in Figure $7 \mathrm{c}$ are due to small snow and ice amounts in the winter time and very limited canopy storage changes. The added substantial negative $\Delta S$ are dominated by deeper soil water extraction, aquifer changes and canopy storage changes.

The simulated partitioning of the energy budget is shown in Figure 9b. Again only the results for FAO texture are shown, because there is hardly any difference between the relative partitioning for the two texture choices. Latent heat $\lambda$ ETa consumes most of the energy, followed by sensible heat $H$ and ground heat flux $G$, respectively. While the observed and simulated magnitude of $G$ is similar, the relative distribution of $\lambda \mathrm{ETa}$ and $H$ is very different, with a much larger simulated fraction of $\lambda \mathrm{ETa}$ in the summer than observed and a very small fraction in the winter. Unlike the observed $\mathrm{Rn}$, the monthly simulated $\mathrm{Rn}$ reaches very small and even some negative values in winter months (December 2002, December 2003). The very low or negative $\mathrm{Rn}$ often results in small negative $H$ values as well (in addition to the negative $G$, which is usual in the winter). The months with extremely low $\mathrm{Rn}$ are mainly characterized by ice building in surface soil layers, and sometimes thin snow layers. Once soil ice takes a significant portion of the soil porosity, $\lambda E$ Ta nearly stops and freezing temperatures cause the $\mathrm{Rn}$ and $H$ to be negligible or negative, which in turn makes the residual $G$ also negligible. The very low simulated $\mathrm{Rn}$ (caused by an overestimated Rnl), accompanied by an underestimated $\lambda E T a$, and possible freeze and thaw effects in the winter time are not found in the 'observations'. However, it is uncertain which energy partitioning is most realistic, because (i) observations on freeze and thaw effects were not available and (ii) the 'observed' energy fluxes are derived from another set of closing energy budget equations.

In order to benefit from data-model fusion techniques, we need a correct relative distribution of state variables and fluxes, both in the model and in observed data sets. The observations and models should not only have the same climatology in absolute magnitudes (to avoid bias), but also, and most importantly, in their relative partitioning of different hydrological variable components. Furthermore, if several independent observations (e.g. multisensor) are merged simultaneously (Pan et al., 2008), 
hydrological consistency amongst different observation sources is needed. In this study, the direct measurements of the water budget components can be assumed to be consistent. The 'observed' energy budget components are derived from closing consistent relationships. Likewise, each model produces self-consistent results. However, the open questions are (i) which of both consistent energy and water partitionings best reflects the truth and, most importantly, (ii) how to deal with the discrepancy in energy (in this study) partitioning when observations and simulations are to be merged.

\section{CONCLUSIONS}

Constraint of hydrologic models typically depends on one or a few observed variables and relies on the assumption of a correct internal water and energy budget partitioning for the simulation of unobserved variables. Measurements sufficient to close energy and water budgets are often not available to fully calibrate or constrain land surface models. A subset of the U.S. nationwide SCAN sites is studied for its usefulness and deficiencies in assessing the regional water and energy budget at 16 point locations across the Lower Mississippi River Basin. In parallel, the CLM3.5 model-based water and energy partitioning is evaluated.

Firstly, the observations are analysed to characterize the study area. The local soil texture is found to be a major soil water storage indicator. Soil moisture levels are more stagnant in lower elevation regions with a higher clay percentage, whereas areas with greater sand percentages show a less dampened reaction to meteorological forcings and contribute more to the discharge variability. When averaged over the entire study region, the monthly averaged soil moisture (SM) anomalies show an autocorrelation length up to 2 months and the cross-correlation with precipitation remains positive for a few weeks, highlighting the system causality and giving an indication of the land system memory. A significant anti-correlation between SM and ETa is found both on the daily and monthly scale. This indicates that, for most of the year, ETa is not limited by soil moisture in this area, and ETa controls SM rather than vice versa. The NDVI anomalies show a positive (resp. negative) correlation with SM (resp. ETa) anomalies, mainly during the summer and early fall months. The NDVI is therefore a potential indicator for hydrological and agricultural drought in these seasons.

Secondly, the consistency in the independently observed components is checked and the CLM-based water and energy budget partitioning is evaluated. CLM simulations with different soil texture parameterizations show only minor differences in water and energy partitioning. The soil parameters mainly affect SM and D, while ETa and energy fluxes are almost unaltered. Both the observed and simulated water budget components show a similar partitioning of the incoming precipitation, but the observed water balance does not close because of measurement errors (precipitation/irrigation error), the lack of storage measurements on aquifer water, soil ice, snow and canopy water changes, and errors in the empirical equations to estimate the actual ETa. The observationbased energy budget components are derived from internally consistent equations (because the SCAN observations do not allow to provide independent measurements) and they differ from the CLM-simulated energy partitioning. The simulated net radiation $\mathrm{Rn}$ reaches smaller values than observed in the winter, the sensible heat $H$ is generally underestimated, but the mean $(\lambda)$ ETa magnitude corresponds to the observed one, while the amplitude is underestimated. Furthermore, the simulations show unobserved freeze and thaw effects in the energy fluxes.

Thirdly, the above insights in the energy and water partitioning allow the identification of observational network deficiencies and model physical understanding. The lack of accurate energy flux measurements to constrain models and the need for accurate precipitation data to drive models remain important issues. Furthermore, incomplete knowledge of freeze and thaw processes in the root zone hamper an accurate budget inventory. Future satellite missions, like Soil Moisture Active and Passive (SMAP, Entekhabi et al., 2010) may help us fill in these shortcomings globally. Different observed and simulated energy and water partitionings based on different theoretical methods have implications for model parameter calibration, state updating (model-data fusion), and simulation of unobserved variables. Depending on the study area, some water or energy fluxes may be more or less sensitive to updating or constraining the model with particular observed state variables. For example, in our small study area within the Lower Mississippi River Basin, SM has a significant impact on runoff and drainage, but it does not control ETa, and hence updating a model with SM observations could improve discharge estimates, but not ETa estimates. To fully constrain the water and energy partitioning, a set of internally consistent observations for different variables may be needed

\section{ACKNOWLEDGMENTS}

Gabriëlle De Lannoy is a postdoctoral research fellow of the Research Foundation Flanders (FWO). We thank Bruno Samain and Valentijn Pauwels for discussing some topics on evapotranspiration.

\section{REFERENCES}

Adegoke JO, Carleton AM. 2001. Relations between soil moisture and satellite vegetation indices in the U.S. corn belt. Journal of Hydrometeorology 3: 395-405.

Allen RG, Jensen ME, Wright JL, Burman RD. 1989. Operational estimates of reference evapotranspiration. Agronomy Journal 81: $650-662$.

Allen RG, Pereira L, Raes D, Smith M. 1998. Crop evapotranspiration - guidelines for computing crop water requirements FAO irrigation and drainage. Technical Report 56, Food and Agriculture Organization of the United Nations (FAO): Rome; http://www.fao.org/docrep/X0490E/x0490e00.HTM. 
Barr AG, King KM, Gillespie TJ, Hartog G, Neumann HH. 1994. A comparison of bowen ratio and eddy correlation sensible and latent heat flux measurements above deciduous forest. Boundary Layer Meteorology 71: 21-41.

Bastiaanssen WGN, Menenti M, Feddes RA, Holtslag AM. 1998. A remote sensing surface energy balance algorithm for land (SEBAL) 1. Formulation. Journal of Hydrology 212-213: 198-121.

Bastidas LA, Gupta HV, Sorooshian S, tleworth WJS, Yang ZL. 1999. Sensitivity analysis of a land surface scheme using multicriteria methods. Journal of Geophysical Research 104(D16): 19.481-19.490.

Betts A, Ball J, Viterbo P. 1999. Basin-scale surface water and energy budgets for the Mississippi from the ECMWF reanalysis. Journal of Geophysical Reseach 104: 19.393-13.306.

Bonan G, Stillwell-Soller LM. 1998. Soil water and the persistence of floods and droughts in the Mississippi river basin. Water Resources Research 34(10): 2693-2701.

de Bruin H, van den Hurk B, Kohsiek W. 1995. The scintillation method tested over a dry vineyard area. Boundary-Layer Meteorology 76: 25-40.

Brutsaert W. 1982. Evaporation into the Atmosphere. Kluwer Academic Publishers.

Clapp RB, Hornberger GM. 2006. Evapotransporation dynamics at an ecohydrological restoration site: an energy balance and remote sensing approach. Journal of the American Water Resources Association 42(3): $565-582$.

De Lannoy GJM, Houser PR, Pauwels VRN, Verhoest NEC. 2006. Assessment of model uncertainty for soil moisture through ensemble verification. Journal of Geophysical Research 111(D10): D10101.1-D1010.18. DOI:10.1029/2005JD006367.

De Lannoy GJM, Reichle RH, Houser P, Pauwels VRN, Verhoest NEC. 2007. Correcting for forecast bias in soil moisture assimilation with the ensemble kalman filter. Water Resources Research 43(6): W09410.1 - W0941.14. DOI:10.1029/2006WR00544.

Dirmeyer PA, Schlosser CA, Brubaker KL. 2009. Precipitation, recycling, and land memory: an integrated analysis. Journal of Hydrometeorology 10: 278-288.

Duan Q, Schaake J. 2003. Total water storage in the Arkansas-Red river basin. Journal of Geophysical Reseach 108(D22): 14.1-14.15.

Ebert EE, Janowiak JE, Kidd C. 2007. Comparison of near-real-time precipitation estimates from satellite observations and numerical models. BAMS January: 47-64. DOI:10.1029/2004GL020873.

Entekhabi D, Njoku EG, O’Neill PE, Kellogg KH, Crow WT, Edelstein WN, Entin JK, Goodman SD, Jackson TJ, Johnson J, Kimball J, Piepmeier JR, Koster RD, Martin N, McDonald KC, Moghaddam M, Moran S, Reichle R, Shi JC, Spencer MW, Thurman SW, Tsang L, Van Zyl J. 2010. The soil moisture active and passive (SMAP) mission. Proceedings of the IEEE 98(5): 704-716.

Feng X, Houser P. 2008. An investigation of GSWP-2 Mississippi River basin surface water and energy budgets. Journal of Geophysical Reseach 113(D15118): 1-14.

Gavin H, Agnew CA. 2004. Modelling actual, reference and equilibrium evaporation from a temperate wet grassland. Hydrological Processes 18: $229-246$.

Goodison BE. 1978. Accuracy of Canadian snow gauge measurements. Journal of Applied Meteorology 27: 1542-1548.

Gu Y, Brown J, Verdin J, Wardlow B. 2007. A five-year analysis of MODIS NDVI and NDWI for grassland drought assessment over the central great plains of the united states. Geophysical Research Letters 34: L06407.1-L06407.XX. DOI:10.1029/2006GL029127.

Gupta HV, Sorooshian S, Yapo PO. 1998. Toward improved calibration of hydrological models: multiple and noncommensurable measures of information. Water Resources Research 34(4): 751-763.

Hargreaves GH. 1975. Moisture availability and crop production. Transactions of the American Society of Agriculture Engineering 18(5): 980-984.

Hargrove W, Hoffman F, Law B. 2003. New analysis reveals representativeness of Ameriflux network. Earth Observing System Transactions, American Geophysical Union 84(48): 529.

Kite GW, Droogers P. 2000. Comparing evapotranspiration estimates from satellites, hydrological models and field data. Journal of Hydrology 229: 3-18.

Massman W, Lee X, Law BE. 2004. Handbook of Micrometeorology. A Guide for Surface Flux Measurements and Analysis. Kluwer Academic Publishers: Boston; 250.

Maurer EP, Wood AW, Adam JC, Lettenmaier DP. 2002. A long-term hydrologically based dataset of land surface fluxes and states for the conterminous United States. Journal of Climate 15: 3237-3251.
Meijninger WML, de Bruin H. 2000. The sensible heat fluxes over irrigated areas in western Turkey determined with a large aperture scintillometer. Journal of Hydrology 229(1-2): 42-49.

Mostovoy GV, Anantharaj VG. 2008. Observed and simulated soil moisture variability over the lower Mississippi delta region. Journal of Hydrometeorology 9: 1125-1150.

Norman J, Kustas W, Prueger J, Diak G. 2000. Surface flux estimation using radiometric temperature: a dual-temperature-difference method to minimize measurement errors. Water Resources Research 36: $2263-2274$.

Oleson KW, Niu G-Y, Yang Z-L, Lawrence DM, Thornton PE, Lawrence PJ, Stockli R, Dickinson RE, Bonan GB, Levis S, Dai A, Qian T. 2007. Improvements to the Community Land Model and their impact on the hydrological cycle. Journal of Geophysical Research 113: G01021. DOI:10.1029/2007JG000563.

Pan M, Wood EF, Wójcik R, McCabe MF. 2008. Estimation of regional terrestrial water cycle using multi-sensor remote sensing observations and data assimilation. Remote Sensing of Environment 112: $1282-1294$.

Pauwels V, De Lannoy G. 2010. Multivariate calibration of a water and energy balance model in the spectral domain: recommendations for efficient parameter estimation. Water Resources Research in review.

Pauwels V, Samson R. 2006. Comparison of different methods to measure and model actual evapotranspiration rates for a wet sloping grassland. Agricultural Water Management 82: 1-24.

Peters-Lidard CD, Blackburn E, Liang X, Wood EF. 1998. The effect of soil thermal conductivity parameterization on surface energy fluxes and temperatures. Journal of atmospheric Sciences 55(7): 1209-1224.

Priestley C, Taylor R. 1972. On the assessment of surface heat flux and evaporation using large-scale parameters. Monthly Weather Review 100: $81-82$

Rasmusson EM. 1968. Atmospheric water transport and the water balance over North America. II. Large-scale water balace investigation. Monthly Weather Review 96: 710-734.

Reynolds C, Jackson TJ, Rawls W. 1999. Estimating available water content by linking the FAO soil map of the world with global soil profile databases and pedo-transfer functions. Proceedings of the AGU 1999 Spring Conference. Boston, MA.

Richter A, Western A, Chiew FH. 2004. The effect of soil and vegetation parameters in the ECMWF land surface scheme. Journal of Hydrometeorology 9: 1131-1146.

Rodell M, Chen J, Kato H, Famiglietti J, Nigro J, Wilson C. 2007. Estimating ground water storage changes in the Mississippi river basin (USA) using GRACE. Hydrogeological Journal 15: 159-166.

Rogers RR, Yau MK. 1989. A Short Course in Cloud Physics. Butterworth-Heinemann, Elsevier.

Schaefer GL, Cosh MH, Jackson TJ. 2007. The USDA natural resources conservation service soil climate analysis network (SCAN). Journal of Atmospheric and Oceanic Technology 24(12): 2073-2077.

Sheffield J, Ferguson CR, Troy TJ, Wood EF, McCabe MF. 2009. Closing the terrestrial water budget from satellite remote sensing. Geophysical Research Letters 36(L07403): DOI:10.1029/2009GL037338.

Shuttleworth WJ. 1992. Evaporation. In Handbook of Hydrology, Maidment DR (ed). McGraw-Hill: New York; 4.1-4.53.

Su H, Wood E, McCabe M, Su Z. 2007. Towards a globally operational evapotranspiration product based on remotely sensed data: evaluation of the SEBS model using the CEOP data. Journal of the Meteorological Society of Japan 85A(0): 439-459.

Syed T, Famiglietti JS, Chen J, Rodell M, Seneviratne SI, Viterbo P, Wilson CR. 2005. Total basin discharge for the Amazon and Mississippi river basins from GRACE and a land-atmosphere water balance. Geophysical Reseach Letters 32(L24404): DOI:10.1029/ 2005GL024851.

Tian Y, Peters-Lidard C, Eylander J, Joyce R, Huffman GJ, Adler R, Hsu K-L, Turk FJ, Garcia M, Zeng Z. 2009. Component analysis of errors in satellite-based precipitation estimates. Journal of Geophysical Research 114: D24101.

Vörösmarty C, Federer C, Schloss A. 1998. Potential evaporation functions compared on US watersheds: possible implications for global-scale water balance and terrestrial ecosystem modeling. Journal of Hydrology 207: 147-169.

Wang X, Xie H, Guan H, Zhou X. 2007. Different responses of MODISderived NDVI to root-zone soil moisture in semi-arid and humid regions. Journal of Hydrology 340: 12-24.

Xu C-Y, Chen D. 2005. Comparison of seven models for estimation of evapotranspiration and groundwater rechage using lysimeter measurement data in Germany. Hydrological Processes 19: 3717-3734. 
Yarosh ES, Repelowski CF, Berbery ED. 1999. Biases of the observed atmospheric water budgets over the central United States. Journal of Geophysical Reseach 104: 19349-19360.

Zaitchik BF, Rodell M, Reichle RH. 2008. Assimilation of GRACE terrestrial water storage data into a 1 and surface model: results for the Mississippi river basin. Journal of Hydrometeorology 9: 535-548.
Zeng XB, Decker M. 2009. Improving the numerical solution of soil moisture-based richards equation for land models with a deep or shallow water table. Journal of Hydrometeorology 10(1): 308-319.

Zeng X, Shaikh M, Dai Y, Dickinson RE, Myneni RB. 2002. Coupling of the common land model to the NCAR community climate model. Journal of Climate 15: 1832-1854. 